NBER WORKING PAPER SERIES

\title{
PPP STRIKES BACK: AGGREGATION AND \\ THE REAL EXCHANGE RATE
}

\author{
Jean Imbs \\ Haroon Mumtaz \\ Morten O. Ravn \\ Hélène Rey \\ Working Paper 9372 \\ http://www.nber.org/papers/w9372

\section{NATIONAL BUREAU OF ECONOMIC RESEARCH \\ 1050 Massachusetts Avenue \\ Cambridge, MA 02138} \\ December 2002
}

We thank Peter Clark, Mick Devereux, Charles Engel, Lutz Kilian, Roberto Rigobon, Barbara Rossi, Ron Smith, Antonio Spilimbergo, Shang-Jin Wei, Charles Wyplosz, and seminar participants at ESSIM 2002, Penn, NYU, Stanford, the IMF and the ESRC Money-Macro Finance conference in Warwick for helpful comments. Parts of this paper were completed while Ravn was a visitor at the University of Pennsylvania, and Imbs and Rey were visitors at the IMF. The authors are grateful to these institutions for their hospitality. The paper is part of the project "Exchange Rates, International Relative Prices, and Macroeconomic Models", funded by the ESRC (grant no.L138 25 1043), and of the RTN programme "The Analysis of International Capital Markets: Understanding Europe's Role in the Global Economy", funded by the European Commission (contract no. HPRN-CT-1999-00067). The views expressed herein are those of the authors and not necessarily those of the National Bureau of Economic Research.

(C) 2002 by Jean Imbs, Haroon Mumtaz, Morten O. Ravn, and Hélène Rey. All rights reserved. Short sections of text, not to exceed two paragraphs, may be quoted without explicit permission provided that full credit, including (C) notice, is given to the source. 
PPP Strikes Back: Aggregation and the Real Exchange Rate Jean Imbs, Haroon Mumtaz, Morten O. Ravn, and Hélène Rey NBER Working Paper No. 9372

December 2002

JEL No. F36, F41, C43

\begin{abstract}
We show the importance of a dynamic aggregation bias in accounting for the PPP puzzle. We prove that established time series and panel methods substantially exaggerate the persistence of real exchange rates because of heterogeneity in the dynamics of disaggregated relative prices. When heterogeneity is properly taken into account, estimates of the real exchange rate half-life fall dramatically, to little more than one year, or significantly below Rogoff's 'consensus view' of three to five years. We show that corrected estimates are consistent with plausible nominal rigidities, thus, arguably, solving the PPP puzzle.
\end{abstract}

Jean Imbs

London School of Business

Regent's Park

NW1 4SA

London, UK

Morten O. Ravn

London School of Business

Regent's Park

NW1 4SA

London, UK
Haroon Mumtaz

London School of Business

Regent's Park

NW1 4SA

London, UK

Hélène Rey

Department of Economics

Princeton University

Fisher Hall

Princeton, NJ 08544

and NBER

hrey@princeton.edu 


\section{Introduction}

The study of real exchange rates, defined as the international relative price of a basket of goods expressed in a common currency, is perhaps the most intensely researched area in international macroeconomics. The principle of absolute purchasing power parity (PPP) states that real exchange rates should be constant and equal to one or, expressed in relative terms, that changes in the real exchange rate should be arbitraged away. Yet the consensus from the empirical literature appears to be that, although real exchange rates may be stationary and tend to converge to parity level in the long run, the rate at which this happens is very slow. The speed of mean reversion is usually summarized by one statistic, the half life, or the time necessary for half the effect of a given shock to dissipate. Estimates of half-lives usually lay in the ballpark of three to five years. ${ }^{1}$ Kilian and Zha (2002) conduct a survey among international economists regarding their views on real exchange rates half-lives. The survey responses are dispersed, but display a single peak around four years, which thus emerges as the 'consensus half-life' in the economics profession. Evidence on the law of one price (LOP) is hardly more encouraging, as it suggests persistent international differences in good prices as well. ${ }^{2}$

If the empirical evidence and international economists are right, these large estimates have three important consequences. Firstly, PPP is at best of little practical relevance over horizons of concern to policymakers or practitioners, who are typically interested in the short to medium run fluctuations of the economy. Secondly, economic models based on the PPP assumption are unlikely to provide an adequate description of the real world at any relatively short horizon. Thirdly, the slow convergence of international prices towards parity makes it quantitatively difficult to ascribe the failure of PPP to temporary arbitrage impediments or sticky prices. This has spawned a literature taking up the challenge of constructing calibrated macroeconomic models with nominal rigidities able to replicate the observed persistence of the real exchange rate. $^{3}$

In this paper, we show how one simple fact accounts for the surprisingly low es-

\footnotetext{
${ }^{1}$ See Rogoff (1996) or Froot and Rogoff (1995) for excellent surveys of the literature. The consensus view is based on panel data estimates, as in Frankel and Rose (1996), Oh (1996), Wu (1996) or Lothian (1997), or on estimates using long spans of data, as in Frankel (1986, 1990), Mark (1995), Lothian and Taylor (1996), Abuaf and Jorion (1990) or Glen (1992). Diebold, Husted, and Rush (1991) look at the Gold Standard and find a similar result. The debate is not over however. A few recent studies, emphasizing non-linearities argue that the true half life is in fact smaller than this consensus estimate (Taylor, Peel and Sarno (2001), Taylor and Peel (2000) or Obstfeld and Taylor (1997)); but some other recent studies argue that it could in fact be much bigger (MurrayPapell (2002c), Engel (2000)) or that the confidence intervals are far too wide to tell (Murray-Papell (2002a), Rossi (2001), Kilian and Zha (2002)). For an interesting recent study on long run PP P see Coakley et al (2002).

${ }^{2}$ Classic studies include Giovannini (1988), Isard (1977), Knetter (1989, 1993), and Richardson (1978). Rogoff (1996) and Goldberg and Knetter (1997) offer recent excellent surveys of the PPP and LOP literatures.

${ }^{3}$ A few examples include Kollman (2001), Chari, Kehoe and McGrattan (2002) and Bergin and Feenstra (2001).
} 
timates of the speed of reversion of the real exchange rate: the failure to account for cross-sectoral heterogeneity in the dynamic properties of the typical price index components. All existing estimates, whether based on panel data or pure time series suffer from a cross-sectional aggregation bias. The speed of reversion to parity depends in all likelihood on goods-specific characteristics, and thus is not homogenous across sectors. ${ }^{4}$ In fact, it is hard to think of reasons why clothes and vegetables, say, should revert to parity at the same speed. ${ }^{5}$ We show how failure to allow for these differences induces a positive bias in aggregate half-lives estimates, and thus stress the importance of correcting for heterogeneity when estimating real exchange rates half-lives. ${ }^{6}$

We investigate the quantitative role of this bias using an international sectoral price database issued by Eurostat. We find the bias to be substantial. As crosssectoral heterogeneity is allowed for, the real exchange rate revert to PPP dramatically faster than estimated previously and, importantly, our estimate of the speed of mean reversion is in line with what reasonable barriers to arbitrage or nominal rigidities would imply. Our estimated median half life is 14 months with a confidence interval ranging from 5 to 24 months. This is far below standard estimates, and not due to any specificities in our dataset, as we are able to reproduce the 'consensus view' when not correcting for heterogeneity. ${ }^{7}$ The intuition for this dramatic result is straightforward. If the persistence of relative prices varies across sectors, but aggregate estimations are calculated under the premise of a unique aggregate autoregressive coefficient, the parameter heterogeneity gives rise to correlation between the regressors and the residuals. We show this correlation to induce a substantial positive bias in the estimate of the persistence of the process, and that the magnitude of this bias increases with the degree of sectoral heterogeneity. ${ }^{8}$ Furthermore, we show that our corrected estimates are in line with the real exchange rate persistence derived in a model with plausible nominal rigidities, due to Chari, Kehoe and McGrattan (2002). Thus in a sense, there is no PPP puzzle.

Our results are robust. In particular, we consider two alternative explanations.

\footnotetext{
${ }^{4}$ In our estimation, we let the speed of mean reversion be good and country specific but find that the most important heterogeneity is really at the sectoral level.

${ }^{5}$ There is increasing empirical support for heterogeneity in the dynamics of relative prices. See for instance Imbs, Mumtaz, Ravn and Rey (2002) or Campa and Goldberg (2002).

${ }^{6}$ This aggregation bias was first pointed out by Robertson and Symons (1992) and further investigated and generalized by Pesaran and Smith (1995). But, to the best of our knowledge, it has never been applied to exchange rates. Furthermore, we show the bias to be systematically positive for positively correlated sectoral relative prices. For an interesting paper studying temporal aggregation issues, see Taylor (2001). We emphasize however that these two types of aggregation biases (temporal and sectoral) are quite distinct conceptually and may well both be present at the same time.

${ }^{7}$ Our results are to some extent comparable to those in Parsley and Wei (1996), who examine the rate of convergence of relative goods prices across U.S. cities and find faster mean-reversion than in the aggregate. Their estimates are derived at the good level so they probably suffer less of the aggregation bias we document.

${ }^{8}$ The positive sign of the bias actually requires relative sectoral prices to be positively autocorrelated, which we unambiguously observe.
} 
First, measurement error could be larger in sectoral data, as it tends to be aggregated away in price indices. This would induce an attenuation bias in the sectoral autoregressive parameters and hence could account for our findings. However, we run formal tests for the presence of error-in-variables, and, for the few cases where it cannot be rejected, use appropriate instrumenting for the variables measured with error. The effect on our estimates of the persistence of relative prices is negligible. Second, a recent strand of literature contends that real exchange rates half-lives may be larger than our -and other- estimates suggest. When the underlying data generating process is highly persistent, as is the case for real exchange rates, standard least squares estimates of the persistence tend to be biased downwards, unless the sample is long. This bias, in turn may translate into abnormally low half-life estimates. Based on this insight, Murray and Papell (2002a) implement the correction suggested in Andrews and Chen (1994) to real exchange rates. Their corrected confidence intervals for the real exchange rate half-life are so wide as to bring the whole 'consensus view' into question. ${ }^{9}$ There are at least two reasons why our low estimates cannot be accounted for by this negative bias. First, our sample is relatively long. Second, the next section provides standard unit-root tests suggestive that our price data is stationary. Furthermore, the aggregation bias we document is of primary concern irrespective of the Andrews-Chen attenuation bias. To further ascertain the relative magnitude of the two types of biases, we provide Monte-Carlo evidence showing that the positive aggregation bias largely dominates the negative one associated with high persistence.

Finally, our results relate interestingly to the existing evidence on the relationship between goods tradeability and relative price persistence. Engel (1999) finds that the variability of the real exchange rate at all horizons is explained mostly by movements in the relative prices of traded goods. This finding is surprising since deviations from the law-of-one-price are intuitively expected to be less persistent for traded goods, more prone to arbitrage than non-traded ones. Our approach provides a natural explanation for this apparent anomaly. We find that the degree of sectoral heterogeneity is higher among traded goods than among non-traded ones. The aggregation bias is therefore more important for the traded good index. This accounts for the higher degree of persistence observed in the relative price of traded goods, and hence for its dominant role in explaining the variability of the real exchange rate, even at long horizons.

The rest of the paper is structured as follows. The next section describes in detail the econometric issue central to our results: the aggregation bias that plagues dynamic panel and time series estimates, when there is sectoral heterogeneity. Section 3 reviews the data and performs basic tests. In sections 4 and 5, we present various existing procedures to estimate half-lives, and reproduce standard results with our data. We then test and allow for sectoral heterogeneity using a Random Coefficient Model. Results change dramatically. Section 6 examines alternative explanations

\footnotetext{
${ }^{9}$ The conclusion that there is not enough information in the aggregate data to pin down reliably the value of the half-life is also consistent with results in Kilian and Zha (2002) obtained in a Bayesian framework. More recently, Murray and Papell (2002b) have argued that Rogoff's consensus view may be rehabilitated on the basis of real exchange rates panel evidence.
} 
to our findings. In section 7 we conduct a detailed analysis of the links between tradability and heterogeneity and relate our results to the literature on real exchange rate variability across traded and non traded sectors. Section 8 concludes.

\section{Aggregation Bias in Theory}

In this section, we present a simple example to illustrate the main econometric issue underlying the results of the paper. For expositional simplicity, we have relegated the proofs to the appendix. Here, as in the appendix, we follow closely the work of Pesaran and Smith (1995) on the inconsistency of the pooled estimators in the context of heterogeneous dynamic panels. We discuss first the aggregation bias in the context of a pooled panel estimator for sectoral relative prices and subsequently turn to the case of the time series estimator for aggregate real exchange rates.

Assume that relative prices are generated by the following $\mathrm{AR}(1)$ processes:

$$
q_{i t}=\alpha_{i}+\lambda_{i} q_{i t-1}+\varepsilon_{i t}
$$

where $i \in[1, . ., N]$ indexes sectors and $t \in[1, . ., T]$ indexes time. The slope coefficients $\lambda_{i}$ are in the stable range $(-1,1)$ and vary across sectors according to

$$
\lambda_{i}=\lambda+\eta_{i}
$$

where $\left\{\eta_{i}\right\}$, the sectoral specific component, is of mean zero and has a finite variance. The $\left\{\varepsilon_{i t}\right\}$ are i.i.d. distributed with constant variance $\sigma^{2}{ }^{10}$

This model will help answering two related questions: what happens when the autoregressive processes in relative prices are estimated without allowing for parameter heterogeneity, and what happens through aggregation of relative sectoral prices into the real exchange rate.

\subsection{Inconsistency of the Pooled Estimator}

The first case we examine relates to the panel estimator of the speed of adjustment where one does not allow for heterogeneity in the autoregressive parameter. The pooled regression, where a common slope is imposed for all sectors is given by

$$
q_{i t}=\alpha_{i}+\lambda q_{i t-1}+v_{i t}
$$

\footnotetext{
${ }^{10}$ These assumptions are made for simplicity. As will become clearer, under extreme assumptions on the disaggregated residual variances, it is possible for our aggregation bias to become negative. In the estimation however, we let innovation variances vary across sectors. In results available upon request, we also allow for non-zero innovation covariances. Since we repeatedly show the bias to be positive, we conclude these simplifying assumptions are warranted by the data, and are not driving our results.
} 
with

$$
v_{i t}=\varepsilon_{i t}+\eta_{i} q_{i t-1}
$$

When sector specific heterogeneity $\eta_{i}$ is not accounted for, the error term $v_{i t}$ includes lagged relative prices, and is correlated with the regressor as a result. The pooled estimator is therefore inconsistent. Standard instrumentation will not alleviate the bias, since by definition any instruments must be highly correlated with $q_{i t-1}$, but then will unavoidably also be correlated with the error term.

In the presence of fixed effects, i.e. group specific intercepts, it is standard to first difference the data. Here however, the set of regressors includes a lagged dependent variable, which requires estimating $\lambda$ with appropriate instrumenting of the lagged dependent variable by its own lagged values, because of the induced correlation between $q_{i t-1}$ and $v_{i t-1}$ in first differences. ${ }^{11}$ In the presence of parameter heterogeneity however, this will still be inconsistent since any instrument $\triangle q_{i t-k}$ or $q_{i t-k}$ with $k>1$ will be correlated with $\triangle v_{i t}$. In other words, one cannot find any instrument that is both highly correlated with the regressors and orthogonal to the error terms. ${ }^{12}$

We show in Appendix A that the bias of the pooled estimator can be expressed as follows:

$$
\widehat{\lambda}-\lambda=\frac{E\left(\frac{\eta_{i}}{1-\lambda_{i}^{2}}\right)}{E\left(\frac{1}{1-\lambda_{i}^{2}}\right)}
$$

where $\widehat{\lambda}$ denotes the probability limit of the fixed-effects estimator of $\lambda$. The bias is zero in the absence of heterogeneity, and we prove in Appendix A that it is unambiguously positive for $0<\lambda_{i}<1$, a very weak restriction in our application. It is straightforward to show that the magnitude of the bias is increasing with the degree of sectoral heterogeneity. Based on the pooled regression, one would therefore overestimate the half-life of the real exchange rate, and all the more so when the speeds of mean reversion across goods are highly heterogeneous.

\subsection{Inconsistency of the Aggregate Estimator}

A standard technique to deal with heterogeneity is to aggregate the data, ie. in our application, to examine real exchange rates rather than goods-level or sectorlevel relative prices. However, as shown by Pesaran and Smith (1995), the aggregate estimates will also be biased because of sectoral heterogeneity. Assume that each

\footnotetext{
${ }^{11}$ See Anderson and Hsiao (1982) for an IV procedure, and Arellano and Bond (1991) for a GMM estimator.

${ }^{12}$ These instrumental variables procedures will also result in substantial (possibly infinite) autocorrelation in the error terms, since the residuals then embed heterogeneity itself, quite possibly close to being time-invariant.
} 
sector receives equal weight in the aggregate price index in all countries. ${ }^{13}$ The aggregate real exchange rate is then given by:

$$
q_{t}=\frac{1}{N} \sum_{i=1}^{N} q_{i, t}
$$

If we estimate a simple $A R(1), q_{t}=\lambda q_{t-1}+e_{t}$, the error term is given by

$$
e_{t}=\overline{\varepsilon_{i, t}}+\frac{1}{N} \sum_{i=1}^{N} \eta_{i} q_{i, t-1}
$$

where $\overline{\varepsilon_{i, t}} \equiv \frac{1}{N} \sum_{i=1}^{N} \varepsilon_{i t}$. Just as previously, the error term $e_{t}$ comprises the lagged dependent variable through unaccounted heterogeneity, resulting in inconsistency. The positive bias we highlighted for the pooled estimator obtains identically for the aggregate estimator, with the same result on the real exchange rate persistence estimates. ${ }^{14}$

A simple case might be useful in gaining intuition for the result that the bias is positive. Consider a simple case where the econometrician is examining aggregate information on the average relative prices between two economies, each with two sectors, 1 and 2, and she seeks to estimates the auto-regressive properties of the real exchange rate $x_{t}$. To rule out any composition effects and for simplicity, assume the expenditures are shared equally between the two sectors in the two countries, so that $x_{t}=\frac{x_{1+}+x_{2+}}{2}$. Assume further that, unbeknownst to the econometrician,

$$
\begin{aligned}
& x_{1 t}=\theta_{1} x_{1 t-1}+e_{1 t} \\
& x_{2 t}=\theta_{2} x_{2 t-1}+e_{2 t}
\end{aligned}
$$

with $E\left(e_{1 t} e_{2 t}\right)=0, E\left(e_{i t} e_{i s}\right)=0$ for $s \neq t, E\left(e_{i t} e_{i t}\right)=\sigma^{2}$ and $E\left(e_{i}\right)=0 .{ }^{15}$ Assume further some sectoral heterogeneity, for instance, without loss of generality, that $\theta_{1}>$ $\theta_{2}$. Then we have

$$
\begin{aligned}
x_{t} & =\theta_{1} \frac{x_{1 t-1}}{2}+\theta_{2} \frac{x_{2 t-1}}{2}+e_{t} \\
& =\left(\bar{\theta}+\frac{\theta_{1}-\theta_{2}}{2}\right) x_{t-1}-\frac{\theta_{1}-\theta_{2}}{2} x_{2 t-1}+e_{t}
\end{aligned}
$$

\footnotetext{
${ }^{13}$ This assumption is irrelevant for the point that we wish to make. Applying any weighting scheme will produce the same qualitative result. This is an important point because the bias that we highlight will arise as a result of any aggregation of the data and is not due to differences in expenditure weights studied by Crucini et al. (2001), among others.

${ }^{14}$ The bias will be potentially present in any aggregated data, and indeed quite possibly even at the two-digit level. We note however that the extent of the bias increases with heterogeneity, which might be more prevalent between sectors than, say, between firms in the same activity. Careful examination of this question requires data that to our knowledge do not exist.

${ }^{15}$ These assumptions are inessential for the results. It is easy to see that the proof still holds for non-zero cross-sectoral covariances and innovations variances that vary across sectors. In what follows, we allow for sector-specific innovation variances. In results available upon request, we allow for non-zero cross-sectoral covariances. The bias always remains positive and large.
} 
where $\bar{\theta}=\left(\frac{\theta_{1}+\theta_{2}}{2}\right)$ is the true persistence of the real exchange rate, and $e_{t}=\frac{e_{1+t e} t}{2}$. The simple OLS estimate of the autoregressive coefficient of the real exchange rate will be given by $\widehat{\theta}=E\left(x_{t} x_{t-1}\right) / \sigma_{x}^{2}$, where $\sigma_{x}^{2}=E\left(x_{t} x_{t}\right)$. However, since the numerator is given by

$$
E\left(x_{t} x_{t-1}\right)=\left(\bar{\theta}+\frac{\theta_{1}-\theta_{2}}{2}\right) \sigma_{x}^{2}-\frac{\theta_{1}-\theta_{2}}{4} \sigma_{x_{2}}^{2}
$$

with $\sigma_{x_{2}}^{2}=E\left(x_{2 t} x_{2 t}\right)$, the OLS estimate of the real exchange rate persistence will be

$$
\widehat{\theta}=\bar{\theta}+\frac{\theta_{1}-\theta_{2}}{2}\left(1-\frac{\sigma_{x_{2}}^{2}}{2 \sigma_{x}^{2}}\right)
$$

Assuming that $0<\theta_{i}<1$ the assumption on sectoral heterogeneity implies $\sigma_{x_{1}}^{2}>\sigma_{x_{2}}^{2}$, which in turn results in $2 \sigma_{x}^{2}>\sigma_{x_{2}}^{2}$, and $\widehat{\theta}>\bar{\theta}$. QED. It should be clear that the argument generalizes to a continuum of sectors, no matter the expenditure weights used in aggregating. To see this, define $\Delta=1-\frac{\sigma_{x}^{2}}{2 \sigma_{x}^{2}}>0$. The OLS aggregate estimate can be rewritten

$$
\widehat{\theta}=\theta_{1} \frac{1+\Delta}{2}+\theta_{2} \frac{1-\Delta}{2}
$$

OLS gives a larger weight to the more persistent component of the real exchange rate, resulting in apparently large aggregate persistence. Also, the bias increases with the discrepancy between $\theta_{1}$ and $\theta_{2}$, i.e. with the extent of sectoral heterogeneity in this simple two-sector case. Appendix A generalizes both these results for a continuum of sectors.

\section{Data}

Given the hypothesis of parameter heterogeneity at the disaggregate level, we study relative prices of goods at the sectoral level. We use price data obtained from Eurostat, the statistical agency of the European Union. We focus on the (non-harmonized) price indices for consumption goods and services. ${ }^{16}$ The data are available at the monthly frequency and cover at most the period 1960:1 to 2000:12. However, many observations are missing before 1975 and after 1996, so we choose to focus on a $[1975,1996]$ sample. This leaves us with a maximum of 264 time series observations.

Eurostat reports two-digit sectoral price indices for nineteen goods categories and thirteen countries. The good categories are a mixture of low and high unit costs goods (e.g. bread and cereals versus vehicles), highly tradeable goods (e.g. clothing) and goods commonly construed as non-tradeable in nature (public transport or hotels),

\footnotetext{
${ }^{16}$ Eurostat also produces harmonized price indices but these are available only for short sample periods seriously limiting any time-series approaches.
} 
and goods for which there is wide variation in the degree of product differentiation (fuel versus sound and photographic equipment). We provide a detailed description of our data in Appendix B. Our sample thus constitutes an interesting cross-section with some variation along the dimensions commonly advanced to explain variations in relative prices. The cross-sectional variation is key to our analysis since it allows us to focus on the heterogeneity in the dynamics of relative prices.

Our real exchange rates are CPI-based and defined against the US dollar. Since the purpose of our study is to investigate the effects of aggregation, our sample of countries and the time coverage are identical for the two levels of aggregation. Furthermore, our measure of real exchange rates is based on the aggregation of the same exact sample of goods for which we have disaggregated information. Thus we avoid composition effects. $^{17}$

We tested for unit roots both for aggregate real exchange rates and for sectoral real exchange rates. We used two panel data tests: Levin and Lin (1993) and Im, Pesaran and Shin (1997). The Levin and Lin procedure (henceforth LL) tests the hypothesis that all the cross-sectional units are stationary against the hypothesis that they are all non-stationary. The Im, Pesaran and Shin test (henceforth IPS) is more general in that it allows for some, but not all, of the series to be stationary under the alternative hypothesis. ${ }^{18}$ We report in Table 1 the results for these two tests, which are among the most general unit root tests for panel data. The first column reports the outcome of several unit root tests for the panel of aggregate real exchange rates. The third column concerns the panel of sectoral real exchange rates. In each case we report the IPS test and two variations of the LL test, allowing or not for individual effects. Each estimation is run with or without a trend term. Table 1 shows that the hypothesis of unit root in the real exchange rate can be rejected in all cases at standard levels of confidence. Like most of the literature, we find unequivocal evidence in favor of stationarity both for aggregate real exchange rates and for sectoral real exchange rates. ${ }^{19}$ Having checked for stationarity, we will in the remainder of the paper concentrate on the estimation of half-lives at the sectoral and aggregate levels. ${ }^{20}$

\footnotetext{
${ }^{17}$ We also used real exchange rate measures based on the International Financial Statistics database released by the IMF. The results, based on standard CPI baskets, were almost identical.

${ }^{18}$ Taylor and Sarno (1998) introduce a panel estimation that allows for heterogeneity in the regressors coefficients, as well as taking advantage in the possible correlation of the residuals. They use Seemingly Unrelated Regressions techniques that require the time dimension $T$ to exceed the cross-section $N$ in the panel. We cannot use this procedure given the large cross-sectional dimension of our sectoral data.

${ }^{19}$ Frankel and Rose (1996) rejects the unit root hypothesis in a panel of 150 countries over 45 years. So does Oh (1996) in a similar study. Wu (1996), studies monthly and quarterly data from the IFS database and also rejects non-stationarity in a panel setting. Lothian (1997) focuses upon the post Bretton-Woods period and rejects non-stationarity of the real exchange rate in a panel that includes 23 OECD countries.

${ }^{20}$ Stationarity is not crucial for the purpose of this paper. However, the estimations we have described all implicitly assume stationary relative prices, which turns out to be supported by our data.
} 
The econometric approach in this paper is innovative for three reasons: firstly, we use monthly data, something still relatively infrequent in the literature, which affords us a particularly rich dynamic specification. Secondly, we use two strictly comparable samples which differ only by the level of aggregation of the data. Thirdly and most importantly, we show that accounting for sectoral heterogeneity is very important in pooled panel estimations as well as in time series estimation of the aggregate real exchange rate. Thus, we relate the evidence on disaggregated relative prices, concerned with the Law of One Price, to the aggregate literature, concerned with Purchasing Power Parity. We make the simple point that an overlooked reason for the reportedly slow mean reversion of aggregate real exchange rates is the failure to account for cross-sectoral heterogeneity.

\section{Econometric Methods}

We first present estimation procedures widely used in the real exchange rate literature, namely the fixed effects, Anderson-Hsiao and Arellano-Bond estimators. We use them to reproduce existing results with our data. From Section 2, we know none of these estimators are appropriate when there is sectoral heterogeneity in the dynamic parameters. We then present a random coefficient model (RCM) estimator that allows for cross-sectoral heterogeneity. We find that the estimates of the speed of real exchange rate reversion increase substantially, so much so that the PPP puzzle effectively disappears. All empirical results are presented in Section 5.

\subsection{Fixed Effect Estimator}

We use the following specification to investigate the speed of mean reversion in relative prices:

$$
q_{i, j, t}=\alpha_{i, j}+\sum_{p=1}^{P} \lambda_{p} q_{i, j, t-p}+\varepsilon_{i, j, t}
$$

where $i(j)$ indexes sectors (countries), $q_{i, j, t}=\ln \left(\frac{e_{i t} \cdot P_{i, j, t}}{P_{i, U S, t}}\right)$, and $e_{j t}$ denotes the nominal exchange rate between country $j$ and the US at time $t$. We allow for the possibility that the intercept be specific to each individual observation, as would for instance be the case if market integration varied by country and/or by sector. But note that the slope coefficient $\lambda_{p}$ is imposed to be the same across the units of the panel. From estimates of $\lambda_{p}$ in equation (1), it is possible to derive the half-life of mean reversion. For $P=1$ these half-lives can be derived analytically but, in general, we rely on the impulse response functions to compute the half-lives. ${ }^{21}$

\footnotetext{
${ }^{21}$ In the case of $P=1$, the half-life is given by $-\ln 2 / \ln \alpha_{1}$.
} 
The possible presence of fixed effects (through $\alpha_{i, j}$ ) in equation (1) requires that the specification be estimated in first differences. As is now well-known, the presence of a lagged dependent variable makes it necessary to use instrumental variables when estimating equation (1) in first-differences. The reason is the possibility that $q_{i, j, t-p}-q_{i, j, t-p-1}$ is correlated with $\varepsilon_{i, j, t}-\varepsilon_{i, j, t-1}$, resulting in biased estimates of the autoregressive coefficients. Anderson and Hsiao (1982) proposed to instrument the differenced lagged dependent variable with its lagged level to alleviate the bias. This instrument is however often too weak, which is why Arellano and Bond (1991) introduced a GMM procedure using all available lags as instruments of the differenced lagged dependent variable. ${ }^{22}$ In Section 5, we report results corresponding to the fixed effects, Anderson-Hsiao and Arellano-Bond estimators.

\subsection{Random Coefficients Model}

Our next step is to explore the cross-sectoral heterogeneity of our panel, i.e. to allow for the possibility that

$$
q_{i, j, t}=\alpha_{i, j}+\sum_{p=1}^{P} \lambda_{i, j, p} q_{i, j, t-p}+\varepsilon_{i, j, t}
$$

with $\lambda_{i, j, p}=\lambda_{p}+\eta_{i, j}^{1}$ and $\alpha_{i, j}=\alpha+\eta_{i, j}^{2}{ }^{23}$ In words, parameter heterogeneity enters equation (2) through the inclusion of an individual-specific random component in the intercept and regressors' coefficients, as in the simple example of Section 2. Failure to take proper care of coefficient heterogeneity in equation (2) results in estimates of the autoregressive coefficients that are biased upwards. As argued by Pesaran and Smith (1995), and developed in Section 2, if the coefficients $\lambda_{i, j, p}$ are heterogenous, none of the procedures described above will generate consistent estimates, particularly not aggregate estimates of mean reversion, even under the appropriate instrumentation of lagged dependent variables. Instead, Pesaran and Smith show that consistent parameter estimates can be obtained via Generalized Least Squares estimation of (2).

We can rewrite equation (2) as

$$
q_{i, j, t}=\alpha+\sum_{p=1}^{P} \lambda_{p} q_{i, j, t-p}+\xi_{i, j, t}
$$

\footnotetext{
${ }^{22}$ Goldberg and Verboven (2001) present results for an estimation similar to ours, but they focus on the relative prices of automobiles only. Their equation (2) is different from our equation (1) in that they include $q_{i, j, t-1}$, a lagged level of the relative price, in the set of independent variables of the differenced version of (1). Our maintained assumption of stationarity enables us to specify (1) in levels, eliminate fixed effects through first differencing, and correct for the bias implied by the presence of lagged dependent variables.

${ }^{23}$ This follows Hildreth and Houck (1968) and Swamy (1970,1971).
} 
with $\xi_{i, j, t}=\varepsilon_{i, j, t}+\eta_{i, j}^{1} \sum_{p=1}^{P} q_{i, j, t-p}+\eta_{i, j}^{2} \equiv \varepsilon_{i, j, t}+X_{i, j, t}^{\prime} \eta_{i, j}$. Consistent GLS estimates of the coefficients of interest in equation (2) are given by an efficient weighted average of the least squares sector-specific point estimates. To see this, rewrite the model as

$$
q_{s}=Z_{s} B_{s}+v_{s}
$$

where $q_{s}=\left[q_{s, 1}^{\prime}, q_{s, 2}^{\prime}, \ldots, q_{s, T}^{\prime}\right]^{\prime}, Z_{s}=\left[1^{\prime}, q_{s}^{\prime}, q_{s-1}^{\prime}, q_{s-2}^{\prime} \ldots\right]^{\prime}$. In the random coefficients model, we assume

$$
\begin{aligned}
B_{s} & =B+\eta_{s} \\
E\left(\eta_{s}\right) & =0, E\left(\eta_{s} \eta_{s}^{\prime}\right)=\Gamma
\end{aligned}
$$

The random coefficient estimator of $B$ is given by

$$
\begin{aligned}
\widehat{B} & =\sum_{s} W_{s} B_{O L S}^{s} \\
W_{s} & =\left(\sum_{s}\left(\Gamma+V_{s}\right)^{-1}\right)^{-1}\left(\Gamma+V_{s}\right)^{-1} \\
V_{s} & =\sigma_{s}^{2}\left(Z_{s}^{\prime} Z_{s}\right)^{-1}
\end{aligned}
$$

where $B_{O L S}^{s}$ denotes the unit specific OLS estimate of the parameters. Furthermore, the estimate of $\widehat{B}_{s}$ can be derived from weighted average of $\widehat{B}$ and $\widehat{B}_{O L S}^{s}$ :

$$
\widehat{B}_{s}=A_{s} \widehat{B}+\left(I-A_{s}\right) B_{O L S}^{s}
$$

where $I$ is the identity matrix and $A_{s}=\left[V_{s}^{-1}+\Gamma^{-1}\right] \Gamma^{-1} .^{24}$

In the presence of heterogeneity in the dynamics of the relative prices, estimators that aggregate the data are biased and inconsistent. ${ }^{25}$ This applies to pooled or fixed effects estimators on sectoral panel data, as well as to standard times series methods used on aggregate real exchange rates. The only consistent estimate of aggregate persistence is obtained from a weighted average of the sectoral persistence parameters. This is exactly what the RCM estimator does and it does so efficiently since the variance-covariance matrix is allowing for parameter heterogeneity. Any other estimator averaging the persistence parameters would merely be consistent: the simplest is the Mean Group Estimator, which performs an arithmetic averaging of each sectoral persistence parameter to derive aggregate half-lives. It can be shown to be unbiased, and asymptotically equivalent to the RCM estimator. ${ }^{26}$

\footnotetext{
${ }^{24}$ For details, see Lee and Griffiths (1979).

${ }^{25}$ And the bias is equivalent to systematically assigning a larger weight to those components of the aggregate series that are most persistent. The same reasoning applies to pooled data.

${ }^{26}$ Our estimates for half-lives are actually even smaller when using a Mean Group Estimator, at 9 months only. These results are available upon request.
} 


\section{Aggregation Bias in Practice: PPP Strikes Back}

In this section we investigate empirically the importance of the aggregation bias by reporting the half lives obtained when we use standard methods (fixed effects, Anderson-Hsiao, Arellano-Bond) and when we use the RCM estimator controlling for sectoral heterogeneity.

\subsection{Results for Aggregate Real Exchange Rates}

We estimate equation (1) using real exchange rates. Countries are indexed by $j$. This exercise corresponds to standard estimates of real exchange rate persistence based on panels of real exchange rates. The regressions take the form

$$
q_{j, t}=\alpha_{j}+\sum_{p=1}^{P} \lambda_{p} q_{j, t-p}+\varepsilon_{j, t}
$$

We first use standard OLS estimates. We then allow for, and test for fixed effects. Finally, we present results for the Anderson-Hsiao and Arellano-Bond estimators.

The results are reported in Table 2. The first row is based on a standard pooled OLS estimator. This leads to an estimate of the half-life in excess of 450 years, with a confidence interval ranging between almost four years and an infinite upper bound. As a large literature has forcefully argued, the homogeneity of all intercepts in equation (3) is questionable. The next row presents therefore results for an OLS estimator allowing for fixed effects. The estimated half-lives drop tremendously. We now find estimates that are in line with the consensus view: using the point estimate in Table 2, the real exchange rate half-life is three years and three months, well into Rogoff's (1996) 'consensus range'. The 95 percent confidence interval is relatively wide, however, spanning a period from just above one year to just below five years. It is clear that failure to take fixed effects into account can seriously bias estimated half-lives, which is also confirmed by a standard Hausman test for the presence of fixed effects. ${ }^{27}$

The presence of fixed effects requires that we first-difference a model with lagged dependent variables. To address the resulting endogeneity bias, we apply both the Anderson-Hsiao and Arellano-Bond estimators. We select $P$ in equation (3) following the recommendation in $\mathrm{Ng}$ and Perron (1995). This amounts to applications of twosided 10 percent-level $t$-type tests for the significance of the coefficient on the longest lag, allowing for a maximum order of $P=36 .{ }^{28}$ We examine the impulse response functions to evaluate the half-lives, and derive 95 percent confidence intervals using

\footnotetext{
${ }^{27}$ The test also rejects the presence of random effects.

${ }^{28}$ For the Arellano-Bond estimator we use a shorter maximum lag length because long lag lengths leads to delicate issues in finding appropriate instruments.
} 
a bootstrap procedure. The last two rows of Table 2 present the estimated half-lives resulting from the Anderson-Hsiao and the Arellano-Bond estimators, respectively. The results differ substantially. The Anderson-Hsiao estimate points to a half-life of nine years, well above existing evidence, quite possibly because of weak instruments. The Arellano-Bond estimate, however, is somewhat lower than simple OLS with fixed effects, at two years and three months. The corresponding 95 percent confidence interval ranges from fourteen months to almost four years, thus largely within the consensus view. Finally, Table 2 reports the probability value of a test for parameter homogeneity. We clearly fail to reject the hypothesis that autoregressive coefficients are equal across countries, which suggests the meaningful heterogeneity in our data occurs across sectors.

Interestingly, the half-life estimate implied by the Arellano-Bond estimator is very similar to the findings in Lothian (1997), based on the post Bretton-Woods floating period. Lothian (1997) finds a half-life of two years, based on an OLS fixed effects regression using annual data. Thus, our results are largely in line with previous evidence. Our preferred estimate of real exchange rate persistence lays in the lower end of the consensus view, with a half-life between two and three years.

\subsection{Results for Sectoral Real Exchange Rates}

We now use data disaggregated by sectors to check for the implications of sectoral heterogeneity. We work with exactly the same panel of sectoral prices that compose the aggregate CPI used in the above analysis, and estimate equation (2) using the Random Coefficients Model. The Random Coefficient Model described in Section 4 generates both estimates that are specific to each heterogenous cross-section and consistent "aggregate" estimates, as shown by Hildreth and Houck (1968).

We present our RCM half-lives in the first row of Table 3. The half-life estimates drop dramatically, to somewhere between four months and two years, with a point estimate of only fourteen months. Furthermore, coefficient homogeneity is resoundingly rejected in the lower panel of Table 3, confirming that any estimation method failing to control for parameter heterogeneity is inconsistent. It is important to recall that this finding also implies that the estimates of the half-lives based on the aggregate prices presented above will be inconsistent. In other words, given that we reject parameter homogeneity at the disaggregate level, the study of real exchange rates will not give an unbiased answer to the question of how persistent price differences 
are..$^{29,30}$

For comparison purposes we report in the second row of Table 3 the estimates implied by a pooled OLS estimator. The half-life jumps to an absurdly high 172 years. This demonstrates the importance of taking parameter heterogeneity into account and quantifies the inconsistency of the estimates that may arise from an assumption of coefficients homogeneity in a pooled sectoral data. Interestingly, allowing for fixed effects reduces this problem considerably, leading to a half-life estimate of two years and three months. This large reduction occurs because country-sector specific intercepts absorb part of the heterogeneity in our dataset. Nevertheless as the Hausman test in the lower panel of Table 3 indicates, it is not only intercepts that are heterogenous in our data, but coefficients are as well. ${ }^{31}$

Figures 1 and 2 present Monte Carlo experiments describing the size of the bias for the first autoregressive parameter across different specifications (RCM, OLS, Fixed effects and Anderson-Hsiao). Figures 1 implements the simulations using the estimates obtained from our RCM model as the data generating process, whereas Figures 2a and $2 \mathrm{~b}$ implement a wide range of alternative data generating processes. Figure 1 focuses on the bias across estimation methods, while Figure 2 illustrates the magnitude of the aggregation bias along two dimensions: underlying persistence of the data generating process, and underlying heterogeneity. For all estimation methods, except the RCM, the bias is positive and quite large, for both data generating processes. This large bias is induced because the aggregation bias is particularly prevalent in dynamic estimations with lagged dependent variables. In particular, in the presence of parameter heterogeneity, the Anderson-Hsiao or Arellano-Bond instrumenting procedures will not correct for the bias they are designed to alleviate. As a result, the dynamic properties of the dependent variables are estimated incorrectly. Figure 2

\footnotetext{
${ }^{29}$ The RCM estimates rely on the premise that sectoral relative prices are uncorrelated. This assumption is potentially questionable. Unfortunately, the problem caused by rank deficiency of the variance-covariance matrix in large panels makes SURE-GLS difficult to implement with our pooled and heterogeneous estimators. We investigate the impact of residual correlation in two ways. First, we extend the Monte-Carlo experiments to allow for non-zero off-diagonal elements in the correlation matrix of the residuals. Second, we apply the Correlated Common Effect estimator (CCE) described in Pesaran (2002) to our RCM and pooled models. This method is not strictly appropriate for dynamic models, but it does provide some indication on the effect of unobserved common factors in the residuals. In both cases, the bias continues to be positive and very large. In particular, if the coefficients are restricted to be the same across cross-sections, the estimated half-life from a pooled CCE is in excess of 200 months. In contrast, a CCE with heterogeneous coefficients produces a half-life of seven months. These results are available upon request.

${ }^{30}$ As a check, we also run our regressions country by country. The results were qualitatively similar but the low number of cross-sections (17) did not allow us to estimate half-lives with satisfactory precision.

${ }^{31}$ The Table also presents results for the Anderson-Hsiao estimator on the disaggregated data. The estimates are extremely high, at around 24 years. This probably happens as the instruments are not only weak, but also strongly correlated with the residuals at all leads and lags, as the infinite confidence interval suggests. The dimension of the matrix of instruments for the fully efficient Arellano-Bond estimator is VERY large in our disaggregated dataset, and we could not implement the estimation, even if only using a subset of instruments.
} 
confirms this bias is very large no matter the persistence properties of the underlying process.

Our point estimate of a fourteen months half-life is well below other results in the literature. Furthermore, it is important to notice that the confidence interval of our estimate does not include the 'consensus view' of three to five years. Our estimates break the consensus, but, rather surprisingly, at the lower end of its range. Unlike previous estimates, a half-life of fourteen months may not be incompatible with economic theory. For instance, Chari, Kehoe and McGrattan (2002) investigate whether a calibrated international business cycle model with nominal rigidities can reproduce the persistence and volatility of the real exchange rate. In a model where price stickiness is assumed to be one-year long, they find that the first-order autocorrelation of the HP-filtered real exchange rate is 0.62 (with a standard deviation of 0.08). Even under alternative preferences specifications, further shocks, and alternative monetary policy rules, this estimate never exceeds 0.77 . Chari et al. label the inability of standard models to reproduce the observed persistence in real exchange rates the persistence anomaly. Our estimates resolve this anomaly. We simulated our estimated process and HP-filtered the resulting series (since these authors HPfilter their model moments). We found an autoregressive coefficient of 0.636 (with a standard deviation of 0.082$).{ }^{32}$ Therefore, while sectoral heterogeneity is missing from their theoretical exercise, the model proposed in Chari, Kehoe and McGrattan (2002) reproduces exactly the dynamics of the real exchange rate when it is properly estimated. There is therefore a sense in which the PPP puzzle is no more.

Our explanation does not preclude the existence of other, different, aggregation biases. For instance, the half-life is defined as the number of periods necessary for half the initial effect of a given shock to disappear. This may be misleading in the presence of heterogeneity in the initial effects of the shock. In particular, if some sectoral relative prices rise while others decrease upon impact, but rise subsequently, the initial change in the aggregate relative price will tend to be small. Aggregate half-life is then bound to be large given the small size of the initial effect, irrespective of the persistence properties in the goods-specific relative prices. Secondly, temporal aggregation biases may also be at play, as described in Taylor (2001). Sampling data at low frequencies makes it impossible to identify a high-frequency adjustment process. We believe that this particular problem is less important for our exercise given our use of monthly data. ${ }^{33}$

\footnotetext{
${ }^{32}$ Our RCM estimates correspond to monthly data, so we transformed the simulated data into quarterly data by point-in-time sampling - just like the actual data. These dat a were then HP-filtered with a smoothing parameter of 1600 as in Chari, Kehoe and McGrattan (2002). We repeated this 1000 times for samples with 160 quarterly observations.

${ }^{33}$ Several recent papers have also studied the impact of non linearities on the estimation of halflives. For instance, Michael, Nobay and Peel (1997), Taylor and Peel (2000), Taylor, Peel and Sarno (2001), Kilian and Taylor (2003) and Imbs, Mumtaz, Ravn and Rey (2002).
} 


\section{Robustness Checks}

The results we obtained controlling for cross-sectoral heterogeneity are striking: our estimated half-lives are dramatically smaller than any previous evidence. In this section we investigate the robustness of our findings. We first assess the importance of measurement error in sectoral data. We then turn to another (downward) bias, recently emphasized in the empirical exchange rate literature.

\subsection{Errors in Variables}

There is a presumption that measurement error is more prevalent in sectoral data than in the aggregate. Indeed, if errors are uncorrelated across sectors, they tend to average away in the aggregate, and the resulting attenuating bias that may arise from examining dis-aggregated data might explain the evidence documented above. ${ }^{34}$ We address the issue in a straightforward manner. In the absence of measurement error, the OLS estimator $\rho^{O L S}$ and an instrumental variable estimator $\rho^{T S L S}$ are both consistent, and the OLS estimator is efficient. However, in the presence of measurement error, the OLS estimator is inconsistent. Therefore, plim $\left(\rho^{O L S}-\rho^{T S L S}\right)$ should be non zero in the presence of measurement errors. We perform a Hausman test along those lines, but take into account parameter heterogeneity. In particular, we carry out these tests at the sectoral level for each of the cross-sectional units.

Let $q_{i t}^{*}$ denote the observed value of the sectoral real exchange rate and $q_{i t}$ its true value. $u_{i t}$ denotes measurement error. The model is given by

$$
q_{i t}^{*}=\sum_{p=1}^{P} \lambda_{i, p} q_{i t-p}^{*}+v_{i t}
$$

where $q_{i t}^{*}=q_{i t}+u_{i t}$ and $\nu_{i t}=-u_{i t}+\sum_{p=1}^{P} \lambda_{i, p} u_{i t-p}+\varepsilon_{i t}$. The lag structure of the model implies that $\left\{q_{i t}, . ., q_{i t-P}\right\}$ are correlated with the error term $\nu_{i t}$. The appropriate instruments for the TSLS estimate are therefore $\left\{q_{i t-P-1}, \ldots, q_{i t-2 P}\right\}$. (Unreported) Hausman tests indicate the null hypothesis that OLS is consistent is rejected only 14 times out of 222 sectors. ${ }^{35}$ This implies that the OLS estimator is inappropriate for those 14 country-sectors only. We therefore re-estimated the RCM model replacing the OLS with a GMM estimator for those 14 cross sections. The results we obtain are reported in Table 4, and are virtually identical to those described in the previous section. We conclude from this exercise that while errors-in-variables is a theoretically possible explanation for our results, we find no evidence of this problem inducing our results, and very little evidence of the presence of measurement errors ${ }^{36}$.

\footnotetext{
${ }^{34}$ Though we do not observe systematically lower half-lives at the sectoral level, thus casting doubt on this alternative explanation right at the outset.

${ }^{35}$ The $\mathrm{P}$ values are available from the authors upon request.

${ }^{36}$ Charles Engel also analyzed this dataset. He suggested a number of corrections to the data,
} 


\subsection{Downward Bias in OLS for Highly Persistent Processes}

For highly persistent autoregressive processes, it is well known that least squares estimators may be biased downward so that the estimates of the persistence of the process are pushed towards zero. Based on work by Andrews and Chen (1994), Murray and Papell (2002a) propose an approximately bias corrected estimator of the impulse response functions of real exchange rates. The obtained impulse response functions lead Murray and Papell (2002a) to conclude that the confidence intervals for the half-lives are so wide that they are basically uninformative. ${ }^{37}$ Murray and Papell (2002b) apply similar methods to a panel of real exchange rates, and find that their best estimates of half-lives, after correcting for the bias, lie exactly in the range of 3 to 5 years, i.e. no lower than Rogoff's 'consensus view' range. ${ }^{38}$ Their conclusion is that 'panels do not help solve the purchasing power parity puzzle'. Finally Murray and Papell (2002c) apply again the Andrews-Chen correction to the dollar-sterling exchange rate, and argue previous estimates of a half-life around 6 years were misguided. Once corrected, their estimates range from 4.5 to 11 years depending on the number of lags included, with confidence intervals ranging from 3-5 years to infinity. They conclude that the purchasing power parity puzzle is worse than one thinks.

Thus, the potentially negative bias in the estimates of the half-lives due to high persistence of the underlying data might be important in the present context, as it could contribute to explaining our surprisingly low estimates. There are however at least three reasons suggesting the bias is largely irrelevant in our data. First, our panel is unusually large, both in the time and cross-sectional dimensions. ${ }^{39}$ Furthermore, based on Monte-Carlo simulations, Rossi (2001) shows the bias starts becoming substantial for half-lives larger than 2 percent of the time dimension of the data. Using our preferred estimate of 14 months, this ratio is equal to 5.3 percent in our data, but is much lower than this if we take into account the panel dimension. ${ }^{40}$ Second, for the bias to be quantitatively important the autoregressive processes must be very persistent. Once again, the average persistence at the sectoral level - for the reasons that we have discussed - is much lower than at the aggregate level. ${ }^{41}$ Third

detailed at www.ssc.wisc.edu/ ${ }^{\sim}$ cengel/data/Eurostat/EuropeData.htm)).. We implemented all our estimates using the data thus corrected, without any effect on the conclusions. These results are available upon request.

${ }^{37}$ This was confirmed by Rossi (2001), who provides an asymptotic approximation of the half-life in a local-to-unity setting. Qualitatively similar results have also been obtained by Kilian and Zha (2002) using a different methodology. See also Elliott and Stock (2001).

${ }^{38}$ This is also the conclusion in Cashin and McDermott (2002). They use the same type of near unit root correction method, but also allow for a moving average error structure. They show that real exchange rates half-lives remain firmly -and significantly- within the Rogoff consensus range, even after correcting for the bias.

${ }^{39}$ We have up to 264 periods, and 222 country-sector cross-sectional observations. See Appendix $\mathrm{B}$ for details.

${ }^{40}$ The cross-sectoral dimension is almost certainly relevant in assessing the importance of the bias in our data.

${ }^{41}$ Section 2 showed how the presence of unit-roots in our sectoral data is resoundingly rejected 
and perhaps most importantly, Figures 1 and 2 can be used to ascertain the relative importance of the two biases. If the bias associated with high persistence of the data was important in our data, we should expect our estimated autoregressive coefficients to fall substantially as $\rho$ increases. Although it does happen marginally, it is easy to see on Figure 2 that the heterogeneity induced bias is overwhelmingly more important quantitatively, as estimated autor egressive coefficients increase much faster with $\omega$, a measure of sectoral heterogeneity, than they fall with $\rho$, the true persistence. ${ }^{42}$

\section{Heterogeneity, Tradability and Persistence}

We now ask whether our results linking heterogeneity and persistence are related to the literature seeking to explain deviations from PPP through different degrees of failure of the Law of One Price (LOP) across goods. This literature has characterized four main candidates for accounting for deviations from the LOP: (i) tradeability, as imported goods almost always involve some non-zero trading costs, and thus are not perfectly substitutable with domestic ones, (ii) the presence of (non-tradeable) local costs embedded in the final goods prices, (iii) nominal rigidities and (iv) market power in the production chain. Engel $(1993,1999)$ established that the observed volatility of the real exchange rate can not be ascribed to the influence of a non-traded sector, as an exchange rate based on traded goods only reproduces almost identically the volatility of the standard one. Similarly Rogers and Jenkins (1995) report that the persistence of food prices (interpreted as traded goods) and all other good prices is roughly the same. This has sparked research on alternative properties of the components of aggregate prices indices, in the hope that understanding disaggregated deviations from the LOP would shed light onto aggregate deviations from PPP.

Disaggregated studies can be decomposed in two important sub-categories: those using price indices, and those, more recent, using price levels. The most prominent contribution in the first group is Engel and Rogers (1996), who show the importance of the border in explaining the second moments of relative goods prices. This has typically been taken as evidence in favor of hypotheses (iii) and (iv) above. The second group includes numerous recent empirical contributions attempting to account for the first moments of relative goods prices, or deviations from absolute versions of PPP or the LOP. For instance, Crucini, Telmer and Zachariadis (2001) use an (incomplete) panel of 5,000 goods and services in Europe and show that violations of the LOP

by all standard panel tests. Furthermore, Imbs, Mumtaz, Ravn and Rey (2002) present a detailed account of the cross-section of sectoral half-lives.

${ }^{42}$ Directly performing the bias-correction on our data is not straightforward. The reason is that the large cross-sectional dimension of our panel makes the computation very time intensive. In particular, the bootstrap procedure required for the computation of the corrected estimates is exceedingly slow for our panel RCM estimator. For example, 100 replications, each with 100 draws of the covariance matrix, take about five days on a cutting-edge processor. Since a large number of replications is crucial in assuring accuracy of the estimates, we chose instead to use Monte-Carlo simulations to establish the magnitude of the Andrews-Chen issue in our data. 
are relatively small and that the variations in relative prices across countries reflect aspects of all four hypotheses above. ${ }^{43}$

The present paper provides a way of relating the evidence on good-specific deviations from LOP to the PPP puzzle, and its prevalence even amongst traded goods. In particular, we bridge the gap between the literatures based on good-specific evidence and the aggregate data, in showing the importance of cross-sectoral heterogeneity in deviations from the LOP, and demonstrating how failing to account for this heterogeneity in aggregate series results in misleading estimates. Tables 5 and 6 present results for traded and non-traded goods, respectively. ${ }^{44}$ In each table we list the outcomes of Hausman and Swami tests for parameter heterogeneity, as well as half-life estimates. The results suggest that the degree of heterogeneity across traded-goods is more important than across non-traded ones. Homogeneity is always rejected for traded goods, while the Hausman test cannot reject the null hypothesis of homogeneity for non-traded goods. Half life estimates are consistent with this contrast, as the aggregation bias is substantially more prevalent amongst traded goods. Actually, the bias on fixed-effects estimations amongst non-traded goods is almost non-existent, such is the homogeneity of persistence properties amongst non-traded goods. The bias for traded goods, however, is substantial, and actually larger than when all goods were included in Table 3. A traded-good based real exchange rate is substantially more persistent than the standard aggregate, because it includes relative prices with widely different persistence properties.

The dynamics of relative prices are more homogeneous amongst non-traded than traded goods. While a real exchange rate based on non-traded goods only reverts slowly to parity because of the nature of the goods included, a real exchange rate based on traded goods only should not necessarily be expected to revert any faster to parity, because parameter heterogeneity is a much more serious problem there. In that sense, any quest seeking to establish rapid real exchange rate mean reversion, but without accounting for sectoral heterogeneity, is associated with substantial difficulty, stranded between the rock of the intrinsically slow mean reversion of non-traded goods, and the hard place of traded goods heterogeneity. ${ }^{45}$

This exact same phenomenon may explain why traded-good prices account for most of the variability of real exchange rates, even at long horizons, as shown in

\footnotetext{
${ }^{43}$ Parsley and Wei (2002) use a slightly different dataset, based on goods prices in cities in the US and Japan, to confirm the overwhelming importance of borders in relative prices. A number of papers develop case studies of particular goods' international relative prices. for instance, Haskel and Wolf (2001) and Hassink and Schettkat (2001) study prices of IKEA goods, Goldberg and Verboven (2001) focus on car prices across European countries.

${ }^{44}$ Following Engel (1999), the non-traded sectors include rents, leisure, public transport and hotels. The distinction between traded and non traded is of course too stark. In practice, there is a continuum of degrees of tradability and therefore what is labeled as non-traded is actually partly traded and vice versa.

${ }^{45}$ This is another way of interpreting non-linear estimation efforts, for instance by Kilian and Taylor (2003) or Michael, Nobay and Peel (1997). Presumably, the leading reason why real exchange rate adjustments may be non-linear is the presence of arbitrage costs, which in turn clearly are goodspecific.
} 
Engel (1999). This result is a priori very surprising: differences in traded-good prices should be arbitraged away after a relatively small amount of time, whereas differences in non-traded good prices should be much more persistent. We have demonstrated, however, that due to their heterogeneity, traded-good prices seem more persistent than what they really are. They can hence appear to account for low frequency movements of the real exchange rate. This casts a new light on Engel's results. More formally, let us denote by $q_{j, t}$ (resp. $x_{j, t}$ and $n_{j, t}$ ) the real exchange rate of country $j$ at date $t$ based on all goods in the CPI (resp. traded-good prices and non-traded ones only). Engel decomposes the variability of the real exchange rate in its traded and non-traded components and studies their relative contributions at various horizons. One of his measures of variability at an horizon of $p$ months is the MSE (mean squared error), defined as sum of the squared drift and of the variance of the change in the real exchange rate: $M S E\left(q_{j}\right)=\operatorname{var}\left(q_{j, t}-q_{j, t-p}\right)+\operatorname{mean}\left(q_{j, t}-q_{j, t-p}\right)^{2}$. He finds that the ratio

$$
R=\frac{M S E\left(x_{j}\right)}{M S E\left(x_{j}\right)+M S E\left(n_{j}\right)}
$$

is close to 1 even at horizons up to twenty years. We now show that if aggregation biases are more serious for traded goods, as we found earlier, the ratio is naturally biased towards 1 . Since our data are stationary, the drift term is zero.

Let us suppose that traded-good prices are characterized by an $A R(1)$ :

$$
x_{j, t}=\rho x_{j, t-1}+\varepsilon_{t}
$$

with $\operatorname{var}\left(\varepsilon_{t}\right)=\sigma^{2}$ and all $\left\{\varepsilon_{t}\right\}$ uncorrelated. Similarly we assume that non-traded goods prices are given by:

$$
n_{j, t}=\mu n_{j, t-1}+e_{t}
$$

with $\operatorname{var}\left(e_{t}\right)=\tau^{2}$, all $\left\{e_{t}\right\}$ are uncorrelated and $\left\{\varepsilon_{t}\right\}$ and $\left\{e_{t}\right\}$ are orthogonal. We show in Appendix A (based on the asymptotics) that this representation implies the following expression for Engel's ratio

$$
R=\frac{\frac{1-\rho^{2(p+1)}}{1-\rho^{2}} \sigma^{2}}{\frac{1-\rho^{2(p+1)}}{1-\rho^{2}} \sigma^{2}+\frac{1-\mu^{2(p+1)}}{1-\mu^{2}} \tau^{2}}
$$

For long horizons (high $p$ ), $R$ is increasing in $\rho$, the degree of persistence amongst traded goods, and decreasing in $\mu$, the degree of persistence amongst non-traded goods. Since sectoral heterogeneity is more prevalent amongst traded goods than amongst non-traded ones, $\rho$ is biased upwards more than $\mu$. The ratio $R$ will therefore also be biased upwards, provided heterogeneity is sufficiently high in the traded-good sector. This will happen even if the "corrected measure" of the persistence parameters (by which we mean the $R C M$ estimates) imply lower persistence of traded good price 
differentials, compared to the non traded-good price differentials, which seems to be happening in Tables 5 and $6{ }^{46}$

By using standard fixed effects estimates, we can calculate the $M S E$ ratio. We find that for long horizons, $R$ is around 55 percent. By contrast, if we use our $R C M$ corrected estimates, $R$ drops to 33 percent. ${ }^{47}$ When we correct for the aggregation bias, we therefore find that traded-good prices still account for a sizable portion of exchange rate variability at long horizons, but their importance does not match that of the non-traded goods. ${ }^{48}$ The apparent dominant role of traded goods in explaining the variability of the real exchange rate, even at long horizons, can therefore be traced back to the same aggregation bias that solves the PPP puzzle. In particular, it is because traded goods prices have more heterogeneous dynamics than non-traded ones that an exchange rate based on traded goods only will appear particularly persistent. We show this translates as well into a high contribution of traded goods to the real exchange rate volatility.

\section{Summary and Conclusions}

We present evidence that the standard methods of estimation used in the PPP literature largely overestimate the size of real exchange rates half-lives because they fail to correct for parameter heterogeneity. Heterogeneity in the dynamics of relative sectoral prices is highly plausible theoretically. We prove its existence empirically. We demonstrate that the magnitude of the aggregation bias is increasing in the degree of heterogeneity, and show it is quantitatively large in a standard international sectoral price database including most developed economies. We provide an answer to the puzzling dominant role of traded goods in explaining high real exchange rate persistence and volatility. The dynamics of sectoral relative prices are more heterogenous amongst traded than non-traded goods. Therefore the aggregation bias we document is most prevalent amongst traded goods, where observed persistence and variability are largest as a result, even at long horizons.

We expose our results to thorough robustness checks, including measurement error and other attenuating biases prevalent in the literature on aggregate exchange rates dynamics. Our conclusions withstand the tests. When the correct estimator is used, which allows for parameter heterogeneity, exchange rates revert to parity at a much

\footnotetext{
${ }^{46}$ Notice however that Tables 5 and 6 report the results of a autoregressive specification of the real exchange rate of order higher than one, while the reduced form in this section was obtained using an $\mathrm{AR}(1)$ process. The results were similar however when we computed the ratio using our estimated $\mathrm{AR}(5)$. We present the $\mathrm{AR}(1)$ case because the formulae are more transparent.

${ }^{47}$ See Appendix A for more details.

${ }^{48}$ In the non-corrected case, we do not quite reproduce the very high ratios (close to 1) obtained by Engel. This may be due to i) the differences between his samples and ours, ii) his country specific approach when we use a panel methodology; iii) the inclusion of a drift term from which we abstract since we base the results on the asymptotics and assume stationarity.
} 
higher speed than previously reported in the literature. The aggregation bias we are describing plagues any econometric method which aggregates heterogeneous sectoral data, ranging from pooled panel estimators to simple OLS estimates of real exchange rate persistence. Unbiased estimators of real exchange rates persistence must rely on a proper account of sectoral heterogeneity. For instance, the Random Coefficient Model we implement averages sector-specific persistence parameters using efficient weights; it is therefore both consistent and efficient.

Our point estimate for exchange rates half lives is fourteen months, with a 95 percent confidence interval ranging from four months to two years. This happens in a perfectly standard dataset, which reproduces standard results when standard estimation methods are implemented. Thus, we break the 'consensus view', at the lower end of the range. Furthermore, the revision in the estimate of the persistence of relative prices is sufficiently big to reverse one of the largest puzzles in international economics, the PPP puzzle. Our estimates are compatible with existing calibrated models displaying plausible nominal rigidities. This suggests that parameter heterogeneity could be the answer to the famous PPP puzzle. The vast majority of the economic mechanisms that could theoretically impede price adjustments operate at the good or sectoral level. In this paper, we documented an important reason why these theories should not be expected to prevail in the aggregate if heterogeneity is not accounted for. Standard aggregate estimation methods imply a lot of persistence in the real exchange rate, but we should not expect anything else. 


\section{Appendix A: Analytics}

In this appendix, we derive the expression of the bias of the fixed effect pooled estimator and show that this bias is positive and increasing with the degree of heterogeneity. Notations and assumptions are the same as in Section 2.

The model we consider is:

$$
q_{i t}=\alpha_{i}+\lambda q_{i t-1}+v_{i t}
$$

with

$$
v_{i t}=\varepsilon_{i t}+\eta_{i} q_{i t-1}
$$

\subsection{Derivation of the Bias}

Following Pesaran and Smith (1995), we derive the probability limits of the bias in the fixed effects estimator, by taking probability limits as $T$ approaches infinity and subsequently letting $N$ approach infinity as well. Define $\hat{\lambda}$ the probability limit of the fixed effect estimator of $\lambda$. Letting $W_{n}$ denote the within-transformation matrix operator, upper bars denote time averages, $q$ denote the $N T \mathrm{x} 1$ vector of observations $q_{i t}$ and $q_{-1}$ denote the NTx1 vector of observations $q_{i t-1}$, we have:

$$
\widehat{\lambda}=\left(q_{-1}^{\prime} W_{n} q_{-1}\right)^{-1}\left(q_{-1}^{\prime} W_{n} q\right)
$$

Or

$$
\widehat{\lambda}=\lambda+\frac{\sum_{i=1}^{N} \sum_{i=1}^{T}\left(v_{i t}-\overline{v_{i}}\right)\left(q_{i t-1}-\overline{q_{i,-1}}\right) / N T}{\sum_{i=1}^{N} \sum_{i=1}^{T}\left(q_{i t-1}-\overline{q_{i,-1}}\right)^{2} / N T}
$$

Now

$$
\begin{aligned}
& \operatorname{plim}_{T \rightarrow+\infty}\left(\frac{\sum_{i=1}^{T}\left(v_{i t}-\overline{v_{i}}\right)\left(q_{i t-1}-\overline{q_{i,-1}}\right)}{T}\right) \\
& =\operatorname{plim}_{T \rightarrow+\infty}\left(\frac{\sum_{i=1}^{T}\left(\varepsilon_{i t}-\overline{\varepsilon_{i}}\right)\left(q_{i t-1}-\overline{q_{i,-1}}\right)}{T}\right)+\eta_{i} \operatorname{plim}_{T \rightarrow+\infty}\left(\frac{\sum_{i=1}^{T}\left(q_{i t-1}-\overline{q_{i,-1}}\right)^{2}}{T}\right)
\end{aligned}
$$

The first term is zero, therefore

$$
\operatorname{plim}_{N \rightarrow+\infty, T \rightarrow+\infty} \frac{\sum_{i=1}^{N} \sum_{i=1}^{T}\left(v_{i t}-\overline{v_{i}}\right)\left(q_{i t-1}-\overline{q_{i,-1}}\right)}{N T}=\operatorname{plim}_{N \rightarrow+\infty} \frac{\sum_{i=1}^{N}\left(\frac{\sigma^{2}}{1-\lambda_{i}^{2}}\right) \eta_{i}}{N}
$$


Hence, the bias is equal to:

$$
\widehat{\lambda}-\lambda=\frac{E\left(\frac{\eta_{i} \sigma^{2}}{1-\lambda_{i}^{2}}\right)}{E\left(\frac{\sigma^{2}}{1-\lambda_{i}^{2}}\right)}=\frac{E\left(\frac{\eta_{i}}{1-\lambda_{i}^{2}}\right)}{E\left(\frac{1}{1-\lambda_{i}^{2}}\right)}
$$

\subsection{Sign and Magnitude of the Bias}

The denominator is always positive, therefore $\widehat{\lambda}-\lambda>0 \Leftrightarrow E\left(\frac{\eta_{i}}{1-\lambda_{i}^{2}}\right)>0$. Let $f\left(\eta_{i}\right)$ denote the density function for the random variable $\eta_{i}$. We have $\lambda_{i} \in(0,1) \Longleftrightarrow$ $\eta_{i} \in(-\lambda, 1-\lambda)$. By definition, $E\left(\eta_{i}\right)=\int_{-\lambda}^{1-\lambda} \eta_{i} f\left(\eta_{i}\right) d \eta_{i}=0$. Thus,

$$
E\left(\frac{\eta_{i}}{1-\lambda_{i}^{2}}\right)=\int_{-\lambda}^{0} \frac{\eta_{i}}{1-\left(\eta_{i}+\lambda\right)^{2}} f\left(\eta_{i}\right) d \eta_{i}+\int_{0}^{1-\lambda} \frac{\eta_{i}}{1-\left(\eta_{i}+\lambda\right)^{2}} f\left(\eta_{i}\right) d \eta_{i}
$$

For all $\eta_{i}<0,1-\left(\eta_{i}+\lambda\right)^{2}>1-\lambda^{2}$; conversely for all $\eta_{i}>0,1-\left(\eta_{i}+\lambda\right)^{2}<1-\lambda^{2}$. Hence all the positive $\eta_{i}$ have higher weights than the negative ones in the above expression. Since in $E\left(\eta_{i}\right)$ they have equal weights and since $E\left(\eta_{i}\right)=0$, it follows that $E\left(\frac{\eta_{i}}{1-\lambda_{i}^{2}}\right)>0$. QED.

We note that the magnitude of the bias will be bigger when the asymmetry between the weights will be the larger, i.e. the bigger $1-\left(\eta_{i}+\lambda\right)^{2}$ compared to $1-\lambda^{2}$ when $\eta_{i}<0$ and the smaller $1-\left(\eta_{i}+\lambda\right)^{2}$ compared to $1-\lambda^{2}$ when $\eta_{i}>0$. This asymmetry will be larger when $\left\{\eta_{i}\right\}$ is more dispersed. Hence the magnitude of the bias is increasing with the degree of sectoral heterogeneity.

\subsection{Tradability and Heterogeneity}

In this part, we derive the ratio $R$ presented in Section 7 of the paper and we compute its values using different estimates. Adopting the notations defined in Section 7, we have:

$$
x_{j, t}=\rho x_{j, t-1}+\varepsilon_{t}
$$

$\Rightarrow$

$$
x_{j, t}-x_{j, t-p}=-\left(1-\rho^{p}\right) x_{j, t-p}+\sum_{k=0}^{p} \rho^{k} \varepsilon_{t-k}
$$


$\Rightarrow$

$$
\begin{aligned}
\operatorname{var}\left(x_{j, t}-x_{j, t-p}\right) & =E\left(\sum_{k=0}^{p} \rho^{k} \varepsilon_{t-k}\right)^{2} \\
& =\frac{1-\rho^{2(p+1)}}{1-\rho^{2}} \sigma^{2}
\end{aligned}
$$

Thus, for large enough forecast horizons, the $M S E$ is increasing in the degree of persistence, $\rho$. Similar calculations for non traded goods give:

$$
\operatorname{var}\left(n_{j, t}-n_{j, t-p}\right)=\frac{1-\mu^{2(p+1)}}{1-\mu^{2}} \tau^{2}
$$

Hence

$$
R=\frac{\frac{1-\rho^{2(p+1)}}{1-\rho^{2}} \sigma^{2}}{\frac{1-\rho^{2(p+1)}}{1-\rho^{2}} \sigma^{2}+\frac{1-\mu^{2(p+1)}}{1-\mu^{2}} \tau^{2}}
$$

which is equation (2) in Section 7 of the paper.

\subsubsection{Values of $R$ based on non-bias-corrected estimates}

Our fixed-effect estimates for an $A R(1)$ non corrected for heterogeneity are the following: $\widehat{\rho}=0.978805, \widehat{\mu}=0.949748$ and $\widehat{\sigma}^{2}=0.00144687, \widehat{\tau}^{2}=0.00270299$. We obtain the following values for $R$ at various horizons $p$ in months:

\begin{tabular}{c|ccccccc}
\hline $\mathrm{P}$ & 6 & 12 & 24 & 60 & 100 & 180 & 240 \\
\hline $\mathrm{R}$ & 0.386596 & 0.419738 & 0.470788 & 0.537256 & 0.552377 & 0.555547 & 0.555645 \\
\hline
\end{tabular}

\subsubsection{Values of $R$ based on bias-corrected estimates}

We compute the variance at the sectoral level and use the mean of these variances as an estimate of the overall variance. Our $R C M$ estimates for an $A R(1)$ corrected for heterogeneity are the following: $\widehat{\rho}=0.957804, \widehat{\mu}=0.957338$ and $\widehat{\sigma}^{2}=0.0014399137$, $\widehat{\tau}^{2}=0.0029497499$. We obtain the following values for $R$ at various horizons $p$ in months:

\begin{tabular}{c|ccccccc}
\hline $\mathrm{P}$ & 6 & 12 & 24 & 60 & 100 & 180 & 240 \\
\hline $\mathrm{R}$ & 0.328593 & 0.329056 & 0.3297 & 0.330328 & 0.330391 & 0.330394 & 0.330394 \\
\hline
\end{tabular}




\section{Appendix B: Data}

Table B1

\begin{tabular}{llllll}
\hline \hline & & & & \\
\hline Good & Belgium & Denmark & Germany & Greece & Spain \\
\hline Bread & $801-9611$ & $811-969$ & $761-963$ & $811-9610$ & $811-9610$ \\
Meat & $801-9611$ & $811-969$ & $761-963$ & $811-9610$ & $811-9610$ \\
Dairy & $801-9611$ & $811-969$ & $761-963$ & $811-9610$ & $811-9610$ \\
Fruits & $801-9611$ & $811-969$ & $801-963$ & $811-9610$ & $811-9610$ \\
Tobbaco & $771-9611$ & $781-969$ & $761-963$ & $781-9610$ & $781-9610$ \\
Drinks & $771-9611$ & $811-969$ & $761-963$ & $811-9610$ & $811-9610$ \\
Clothing & $801-9611$ & $811-969$ & $801-963$ & $811-9610$ & $811-9610$ \\
Footwear & $801-9611$ & $811-969$ & $801-963$ & $811-9610$ & $811-9610$ \\
Rents & $801-9611$ & $811-969$ & $761-963$ & $811-9610$ & $801-9610$ \\
Fuel & $751-963$ & $771-963$ & $761-963$ & $791-966$ & $801-9610$ \\
Furniture & $801-9410$ & $811-9410$ & $801-9410$ & $811-9410$ & $811-9410$ \\
Dom.App & $801-9410$ & $811-9410$ & $801-9410$ & $811-9410$ & $811-9410$ \\
Vehicles & $801-9611$ & $811-969$ & $761-963$ & $811-9610$ & $811-9610$ \\
Pub.Trans & $801-9611$ & $811-969$ & $761-963$ & $811-9610$ & $811-9610$ \\
Communic & $801-9611$ & $811-969$ & $761-963$ & $811-9610$ & $811-9610$ \\
Sound & $801-9611$ & $811-969$ & $801-963$ & $811-9610$ & $811-9610$ \\
Leisure & $801-9611$ & $811-969$ & $801-963$ & $811-9610$ & $811-9610$ \\
Books & $801-9611$ & $811-969$ & $761-963$ & $811-9610$ & $811-9610$ \\
Hotels & $801-9611$ & $811-969$ & $761-963$ & $811-9610$ & $811-9610$
\end{tabular}


Table B1 Continued

\begin{tabular}{|c|c|c|c|}
\hline Good & France & Ireland & Italy \\
\hline Bread & $811-9610$ & $891-969$ & $811-9512$ \\
\hline Meat & $811-9610$ & $891-969$ & $811-9512$ \\
\hline Dairy & $811-9610$ & $891-969$ & $811-9512$ \\
\hline Fruits & $811-9610$ & $891-969$ & $811-9512$ \\
\hline Tobacco & $781-9610$ & $891-969$ & $781-941$ \\
\hline Drinks & $811-9610$ & $891-969$ & $811-9512$ \\
\hline Clothing & $811-9610$ & $891-969$ & $811-9512$ \\
\hline Footwear & $811-9610$ & $891-969$ & $811-9512$ \\
\hline Rents & $811-9610$ & $891-969$ & $811-9512$ \\
\hline Fuel & $751-9610$ & $891-969$ & $751-9512$ \\
\hline Furniture & $811-9410$ & na & $811-949$ \\
\hline Dom.App & $811-9410$ & na & $811-949$ \\
\hline Vehicles & $811-9610$ & $891-969$ & $811-9512$ \\
\hline Pub.Trans & $811-9610$ & $891-969$ & $811-9512$ \\
\hline Communic & $811-9610$ & $891-969$ & $811-9512$ \\
\hline Sound & $811-9610$ & $891-969$ & $811-9512$ \\
\hline Leisure & $811-9610$ & $891-969$ & $811-9512$ \\
\hline Books & $811-9610$ & $891-969$ & $811-9512$ \\
\hline Hotels & $811-9610$ & $891-969$ & $811-9512$ \\
\hline \multicolumn{4}{|c|}{ Table B1 Continued } \\
\hline Good & Finland & UK & US \\
\hline Bread & $851-9512$ & $811-9610$ & $811-9610$ \\
\hline Meat & $851-9512$ & $811-9610$ & $811-9610$ \\
\hline Dairy & $851-9512$ & $811-9610$ & $811-9610$ \\
\hline Fruits & $851-9512$ & $811-9610$ & $811-9610$ \\
\hline Tobacco & $851-9512$ & $781-9610$ & $781-9610$ \\
\hline Drinks & $851-9512$ & $811-9610$ & $811-9610$ \\
\hline Clothing & $851-9512$ & $811-9610$ & $811-9610$ \\
\hline Footwear & $851-9512$ & $811-9610$ & $811-9610$ \\
\hline Rents & $851-9512$ & $811-9610$ & $811-9610$ \\
\hline Fuel & na & $751-9610$ & $751-9610$ \\
\hline Furniture & na & $811-9410$ & $811-9410$ \\
\hline Dom.App & na & $811-9410$ & $811-9410$ \\
\hline Vehicles & $851-9512$ & $811-9610$ & $811-9610$ \\
\hline Pub.Trans & $851-9512$ & $811-9610$ & $811-9610$ \\
\hline Communic & $851-9512$ & $811-9610$ & $811-9610$ \\
\hline Sound & $851-9512$ & $811-9610$ & $811-9610$ \\
\hline Leisure & $851-9512$ & $811-9610$ & $811-9610$ \\
\hline Books & $851-9512$ & $811-9610$ & $811-9610$ \\
\hline Hotels & $851-9512$ & $811-9610$ & $811-9610$ \\
\hline
\end{tabular}




\section{References}

[1] Abuaf, Niso and Jorion, Philippe. "Purchasing Power Parity in the Long Run." Journal of Finance, 1990, 45(1), pp. 155-74.

[2] Anderson, T.W and Hsiao, C. "Formulation and Estimation of Dynamic Models using Panel Data." Journal of Econometrics, 1982, 18, pp. 47-82.

[3] Andrews, Donald W.K. and Chen, Hong-Yuan. "Approximately MedianUnbiased Estimation of Autoregressive Models." Journal of Business and Economic Statistics, 1994, Vol. 12 (2), pp. 187-204.

[4] Arellano, Manuel and Bond, Stephen. "Some Tests of Specification for Panel Data: Monte-Carlo Evidence and an Application to Employment Data". Review of Economic Studies, 1991, 58, pp. 277-297.

[5] Bergin, Paul R. and Feenstra, Robert C. "Pricing-to-Market, Staggered Contracts, and Real Exchange Rate Persistence." Journal of International Economics, 2001, 54(2), pp. 333-59.

[6] Brown, B.W. and Newey, W.K. "GMM, Efficient Bootstrapping and Improved Inference", mimeo Rice University, 2001.

[7] Campa, Jose and Goldberg, Linda. "Exchange Rate Pass-Through into Import Prices: A Macro or Micro Phenomenon?" NBER Working Paper 8934, 2002.

[8] Cashin P. and J. McDermott. "An Unbiased Appraisal of Purchasing Power Parity", mimeo IMF, 2002

[9] Chari, V.V, Kehoe, Patrick and McGrattan, Ellen. "Can Sticky Price Models Generate Volatile and Persistent Real Exchange Rates?", Review of Economic Studies, forthcoming 2002.

[10] Coakley J. , R. Flood and M. Taylor. "Long Run Purchasing Power Parity: the First Tests", mimeo IMF, 2002.

[11] Crucini, Mario J., Telmer, Chris J. and Zachariadis, Marios. "Understanding European Real Exchange Rates." Mimeo Vanderbilt University, 2001.

[12] Diebold, Francis X., Husted, Steve and Rush, Mark. "Real Exchange Rates Under the Gold Standard." Journal of Political Economy, 1991, 99(6), pp. 1252-71.

[13] Elliott, Graham, and Stock, James. "Confidence Intervals for Autoregressive Coefficients Near One." Journal of Econometrics, 2001, 103, pp. 155-181.

[14] Engel, Charles. "Long-Run PPP May Not Hold After All." Journal of International Economics, 2000, 51, pp.243-73.

[15] Engel, Charles. "Accounting for U.S. Real Exchange Rates." Journal of Political Economy, 1999, 107(3), pp. 507-38. 
[16] Engel, Charles and Rogers, John. "How Wide is the Border?". American Economic Review, 1996, 86(5), pp. 1112-1125.

[17] Frankel, Jeffrey A. "International Capital Mobility and Crowding-Out in the U.S. Economy: Imperfect Integration of Financial Markets or Goods Markets?" Rik W. Hafer (ed.): How Open is the U.S. Economy? Lexington: Lexington Books, 1986.

[18] Frankel, Jeffrey A. "Zen and the Art of Modern Macroeconomics: A Commentary." William S. Haraf and Thomas D. Willett (eds.): Monetary Policy for a Volatile Global Economy. Washington D.C.: American Enterprise Institute for Public Policy Research, 1990.

[19] Frankel, Jeffrey A. and Rose, Andrew K. "A Panel Project on Purchasing Power Parity: Mean Reversion Within and Between Countries." Journal of International Economics, 1996, 40, pp. 209-25.

[20] Froot, Kenneth and Rogoff, Kenneth. "Perspectives on PPP and Long-Run Exchange Rates." Handbook of International Economics, 1995. Eds. G. Grossman and K. Rogoff, Vol.3, pp 1647-1688, North-Holland, New York.

[21] Giovannini, Alberto. "Exchange Rates and Traded Goods Prices." Journal of International Economics, 1988, 24(1/2), pp. 45-68.

[22] Glen, Jack D. "Real Exchange Rates in the Short, Medium, and Long Run." Journal of International Economics, 1992, 33(1/2), pp. 147-66.

[23] Goldberg, Pinelopi K. and Knetter, Michael M. "Goods Prices and Exchange Rates: What Have We Learned?" Journal of Economic Literature, 1997, 35, pp. 1243-72.

[24] Goldberg, Pinelopi and Verboven, Frank. "The Evolution of Price Dispersion in European Car Markets". Review of Economic Studies, 2001, October, pp. 811848.

[25] Haskel, Jonathan and Wolf, Holger. "Why Does the Law of One Price Fail? A Case Study." Scandinavian Journal of Economics, 103, pp. 545-558.

[26] Hassink, Wolter and Schettkat, Ronald. "On Price Setting for Identical Products in Market without Formal Trade Barriers". IZA Discussion Paper No 315, 2001.

[27] Hildreth, Clifford and Houck, James P. "Some Estimators for a Linear Model with Random Coefficients." Journal of the American Statistical Association, 1968, 63, pp. 584-95.

[28] Im, Kyung So, Pesaran, M. Hashem and Shin, Yongcheol "Testing for Unit Roots in Heterogeneous Panels." DAE Working Paper No. 9526, University of Cambridge, 1997. 
[29] Imbs, Jean, Mumtaz, Haroon, Ravn, Morten O. and Rey, Hélène. "NonLinearities and Real Exchange Rate Dynamics." Journal of the European Economic Association, 2002, forthcoming.

[30] Isard, Peter. "How Far Can We Push the Law of One Price?" American Economic Review, 1977, 67(5), pp. 942-48.

[31] Kiefer, N.M., Vogelsang, T. J. and Bunzel, H. "Simple Robust Testing of Regression Hypotheses", Econometrica, 2000, 68, pp. 695-714.

[32] Kilian, Lutz and Taylor, Mark. "Why is it so Difficult to Beat the Random Walk Forecast of Exchange Rates?" Journal of International Economics, 2003, for thcoming.

[33] Kilian, Lutz and Zha, Tao. "Quantifying the Uncertainty about the Half-Life of Deviations from PPP." Journal of Applied Econometrics, 2002, Vol. 17, 2, pp. $107-125$.

[34] Knetter, Michael M. "Price Discrimination by U.S. and German Exporters." American Economic Review, 1989, 79(1), pp. 198-210.

[35] Knetter, Michael M. "International Comparisons of Pricing-to-Market Behavior." American Economic Review, 1993, 83(3), pp. 473-86.

[36] Kollman, Robert "The Exchange Rate in a Dynamic-Optimizing Business Cycle Model with Nominal Rigidities: a Quantitative Investigation." Journal of International Economics, 2001, 55, pp. 243-62.

[37] Lee, L and Griffiths, W. "The Prior Likelihood and Best Linear Unbiased Prediction in Stochastic Coefficient Linear Models." University of New England Working Papers in Econometrics and Applied Statistics No 1, 1979.

[38] Levin, Andrew and Lin, Chien-Fu. "Unit Root Tests in Heterogeneous Panels." UCSD Working Paper No. 93-56, 1993.

[39] Lothian, James R. "Multi-Country Evidence on the Behavior of Purchasing Power Parity under the Current Float." Journal of International Money and Finance, 1997, 16(1), pp. 19-35.

[40] Lothian, James R. and Taylor, Mark P. "Real Exchange Rate Behavior: The Recent Float from the Perspective of the Past Two Centuries." Journal of Political Economy, 1996, 104(3), pp. 488-509.

[41] Mark, Nelson "Exchange Rate Fundamentals: Evidence on Long-Horizon Predictability." American Economic Review, 1995, 85 (1), pp. 201-218.

[42] Michael, Panos, Nobay, A. Robert and Peel, David A. "Transactions Costs and Nonlinear Adjustment in Real Exchange Rates: An Empirical Investigation." Journal of Political Economy, 1997, 105(4), pp. 862-79. 
[43] Murray, Christian J. and Papell, David H. "The Purchasing Power Parity Persistence Paradigm." Journal of International Economics, 2002a, 56, pp. 1-19.

[44] Murray, Christian J. and Papell, David H. "Do Panels Help Solve the Purchasing Power Puzzle?" Mimeo University of Houston, 2002b.

[45] Murray, Christian J. and Papell, David H. "The Purchasing Power Parity Puzzle is Worse Than You Think: A Note on Long-Run Real Exchange Rate Behavior." Mimeo University of Houston, 2002c.

[46] Ng, Serena and Perron, Pierre. "Unit Root Tests in ARMA Models with DataDependent Methods for Selection of the Truncation Lag". Journal of the American Statistics Association, 1995, 90, pp. 268-281.

[47] Nickell, Stephen. "Biases in Dynamic Models with Fixed Effects." Econometrica, 1981, 49, pp. 1417-46.

[48] Oh, Keun-Yeob. "Purchasing Power Parity and Unit Root Tests Using Panel Data." Journal of International Money and Finance, 1996, 15(3), pp. 405-18.

[49] Obstfeld, Maurice, and Taylor, Alan M. "Nonlinear Aspects of Goods-Market Arbitrage and Adjustment: Heckscher's Commodity Points Revisited." Journal of the Japanese and International Economies, 1997, 11, pp. 441-79.

[50] Parsley, David and Wei, Shang-Jin. "Convergence to the Law of One Price without Trade Barriers or Currency Fluctuations." Quarterly Journal of Economics (November), 1996, pp.1211-36.

[51] Parsley, David and Wei, Shang-Jin. "Explaining the Border Effect: The Role of Exchange Rate Variability, Shipping Costs and Geography." Journal of International Economics, forthcoming 2002.

[52] Pesaran, M. Hashem. "Estimation and Inference in Large Heterogeneous Panels with Cross-Section Dependence." University of Cambridge, 2002, Mimeo.

[53] Pesaran, M. Hashem and Smith, Ron. "Estimating Long-Run Relationships From Dynamic Heterogeneous Panels." Journal of Econometrics, 1995, 68, pp. 79-113.

[54] Richardson, J. David. "Some Empirical Evidence on Commodity Arbitrage and the Law of One Price." Journal of International Economics, 1978, 8(2), pp. 34151.

[55] Robertson, D and Symons, J. "Some Strange Properties of Panel Data Estimators." Journal of Applied Econometrics, 7(2), pp. 175-189.

[56] Rogers, John and Jenkins, Michael. "Haircuts or Hysteresis? Sources of Movements in Real Exchange Rates." Journal of International Economics, May 1995, 38, pp. 339-60. 
[57] Rogoff, Kenneth S. "The Purchasing Power Parity Puzzle." Journal of Economic Literature, 1996, 34, pp. 647-68.

[58] Rossi, Barbara. "Confidence Intervals for Half-life Deviations from Purchasing Power Parity." Mimeo Princeton University, 2001.

[59] Swamy, P. "Statistical Inference in Random Coefficient Regression Models." Springer-Verlag, 1971.

[60] Swamy, P. "Efficient Inference in a Random Coefficient Regression Model." Econometrics, 1970, 38, pp.311-323.

[61] Taylor, Alan M. "Potential Pitfalls for the Purchasing-Power Parity Puzzle? Sampling and Specification Biases in Mean-Reversion Tests of the Law of One Price." Econometrica, 2001, 69, pp. 473-98.

[62] Taylor, Mark and Sarno, Lucio. "The Behavior of the Real Exchange Rate During the Bretton Woods Period". Journal of International Economics, 1998, 46, pp. 281-312.

[63] Taylor, Mark P. and Peel, David A. "Nonlinear Adjustment, Long-Run Equilibrium and Exchange Rate Fundamentals." Journal of International Money and Finance, 2000, 19, pp. 33-53.

[64] Taylor, Mark P., Peel, David A. and Sarno, Lucio. "Nonlinear Mean-Reversion in Real Exchange Rates: Towards a Solution to the Purchasing Power Parity." International Economic Review, 2001, 42(4), pp. 1015-42.

[65] Wu, Yangru. "Are Real Exchange Rates Nonstationary: Evidence from a PanelData Test." Journal of Money, Credit, and Banking, 1996, 28(1), pp. 54-63. 
Table 1: Unit Root Tests

\begin{tabular}{|c|c|c|c|c|}
\hline Test & Trend & $\ln \left(\frac{\left(P_{\left.i * e_{i, u s}\right)}\right)}{P_{u s}}\right)$ & $\mathrm{e}_{i, u s}$ & $\ln \left(\frac{\left(P_{i j} * e_{i, u s}\right)}{P_{u j s}}\right.$ \\
\hline IPS ADF & no & $\begin{array}{l}1.995 \\
{[0.023]}\end{array}$ & $\begin{array}{l}-2.397 \\
{[0.008]}\end{array}$ & $\begin{array}{l}-5.915 \\
{[0.000]}\end{array}$ \\
\hline IPS ADF & yes & $\begin{array}{c}2.505 \\
{[0.006]}\end{array}$ & $\begin{array}{c}0.334 \\
{[0.369]}\end{array}$ & $\begin{array}{l}-4.218 \\
{[0.000]}\end{array}$ \\
\hline LL & no & $\begin{array}{l}-2.030 \\
{[0.021]}\end{array}$ & $\begin{array}{l}-1.800 \\
{[0.036]}\end{array}$ & $\begin{array}{c}-16.901 \\
{[0.000]}\end{array}$ \\
\hline LL & yes & $\begin{array}{l}-1.984 \\
{[0.024]}\end{array}$ & $\begin{array}{l}-1.773 \\
{[0.038]}\end{array}$ & $\begin{array}{c}-16.422 \\
{[0.000]}\end{array}$ \\
\hline $\mathrm{LL}^{1}$ & no & $\begin{array}{c}-11.902 \\
{[0.000]}\end{array}$ & $\begin{array}{l}-8.092 \\
{[0.000]}\end{array}$ & $\begin{array}{l}-7.011 \\
{[0.000]}\end{array}$ \\
\hline
\end{tabular}

Notes: P-values are in the parenthesis. The lag length was chosen via a cross section specific general to specific procedure. All test regressions include an intercept. IPS denotes Im, Pesaran and Shin and LL stands for Levin and Lin. LL ${ }^{1}$ is Levin and Lin test that includes individual effects. 
Table 2: Half Life Estimates using Aggregate Data

\begin{tabular}{lllll}
\hline \hline \multicolumn{4}{c}{$q_{j, t}=\alpha_{j}+\sum_{p=1}^{P} \lambda_{p} q_{j, t-p}+\varepsilon_{j, t}$} & \\
\hline Model & $P$ & $\sum_{p=1}^{P} \lambda_{p}$ & Half Life & Confidence Interval \\
OLS & 12 & 0.9998 & 5589 & $44, \infty$ \\
Fixed Effects & 32 & 0.9733 & 39 & 14,58 \\
Anderson Hsiao & 36 & 0.9905 & 108 & $68, \infty$ \\
Arellano Bond & 12 & 0.9689 & 27 & 14,47 \\
& & & & \\
\hline${ }^{a} H 0: \alpha_{j}=0$ & $3.04(0.0001)$ & \\
${ }^{b} H 0: E\left(\alpha_{j}, X\right)=0$ & $34.33(0.0006)$ & \\
${ }^{c} H 0: \lambda_{j}=\lambda$ & $111.38(0.999)$ & \\
${ }^{d} H 0: \lambda_{j}=\lambda$ & $2.45(0.1175)$ & \\
\hline \hline
\end{tabular}

Notes: The panel is based on aggregate relative prices indices for 13 countries over the period 1975:1 - 1996:12. The choice of $\mathrm{P}$ is based on general to specific lag selection procedure with a maximum lag of 36 for all models except Arellano and Bond where the maximum is 12 . For the GMM estimator five lags of the levels of relative prices were used as instruments. The confidence intervals for the half life estimates were estimated using non-parametric bootstrap with 1500 bootstrap replications for all specifications except Arellano and Bond where they were restricted to 500. Note that the bootstrap for the Arellano and Bond estimator was carried out using the methods described in Brown and Newey (2001). "a" is a test for fixed effects, "b" is the Hausman test, "c" is a Swami test for coefficient homogeneity, while "d" denotes a Hausman type test for homogeneity. 
Table 3: Half Life Estimates using Disaggregate Data

\begin{tabular}{lllll}
\hline \hline \multicolumn{4}{c}{$q_{i, j, t}=\alpha_{i}+\sum_{p=1}^{P} \lambda_{i, p}$} & $q_{i, j, t-p}+\varepsilon_{i, j, t}$ \\
\hline Model & $P$ & $\sum_{j=1}^{P} \lambda_{j}$ & Half Life & Confidence Interval \\
RCM & 5 & 0.9481 & 14 & 5,24 \\
OLS & 12 & 0.9996 & 2063 & $9, \infty$ \\
Fixed Effects & 12 & 0.9698 & 27 & 7,42 \\
Anderson Hsiao & 7 & 0.9974 & 281 & $1, \infty$ \\
& & & & \\
\hline${ }^{a} H 0: \alpha_{i}=0$ & $1.85(0.000)$ & \\
${ }^{b} H 0: E\left(\alpha_{i}, X\right)=0$ & $1196.32(0.000)$ & \\
${ }^{c} H 0: \lambda_{i}=\lambda$ & $2317.37(0.000)$ & \\
${ }^{d} H 0: \lambda_{i}=\lambda$ & $32.68(0.000)$ & \\
\hline \hline
\end{tabular}

Notes: The estimates are based on a panel of relative prices for 19 goods from 13 countries over the period 1975:1 - 1996:12. The lag length $\mathrm{P}$ was chosen via a general to specific lag selection procedure with a maximum lag of 12 for all models. The confidence intervals for the half life estimates are based on 1500 bootstrap replications for all specifications. "a" is a test for fixed effects, "b" is the Hausman test, "c" is the Swami test for coefficient homogeneity, while " $\mathrm{d}$ " is a Hausman type test for coefficient homogeneity. 
Table 4: Errors in Variable in the Disaggregate Data

\begin{tabular}{rllll}
\hline \hline \multicolumn{5}{r}{$q_{i t}^{*}=\sum_{p=1}^{P} \lambda_{i, p} q_{i t-p}^{*}+\varepsilon_{i t}$} \\
\hline Model & $P$ & $\lambda_{j}$ & Half Life & Confidence Interval \\
$\mathrm{RCM}^{1}$ & 5 & 0.94476 & 13 & 4,21 \\
$\mathrm{RCM}^{2}$ & 5 & 0.94642 & 14 & 4,23 \\
\hline \hline
\end{tabular}

Notes: The RCM models are estimated using GMM for 14 cross sections where the Hausman test indicates the inconsistency of OLS. $\mathrm{RCM}^{1}$ uses a covariance matrix constructed via methods described in Kiefer Vogelsang and Bunzel (2000), while RCM ${ }^{2}$ uses a Newey West covariance matrix with a Bartlett Kernel. 
Table 5: Half Life Estimates (Tradeable Goods)

\begin{tabular}{lllll}
\hline \hline \multicolumn{4}{c}{$P_{i, t}=\sum_{j=1}^{P} \lambda_{j} P_{i, t-i}+\varepsilon_{i, t}$} \\
\\
\hline Model & $P$ & $\sum_{j=1}^{P} \lambda_{j}$ & Half Life & Confidence Interval \\
RCM & 5 & 0.94964 & 15 & 4,24 \\
OLS & 12 & 0.99981 & 2493 & $10, \infty$ \\
Fixed Effects & 12 & 0.97532 & 33 & 8,54 \\
Anderson Hsiao & 10 & 0.99261 & 87 & $3, \infty$ \\
& & & \\
\hline${ }^{a} H 0: \alpha_{i}=0$ & $1.72(0.000)$ & \\
${ }^{b} H 0: E\left(\alpha_{i}, X\right)=0$ & $679.80(0.000)$ & \\
${ }^{c} H 0: \lambda_{i}=\lambda$ & $1665.81(0.000)$ & \\
${ }^{d} H 0: \lambda_{i}=\lambda$ & $49.36(0.000)$ & \\
\hline \hline
\end{tabular}

Notes: The lag length $\mathrm{P}$ was chosen via a general to specific lag selection procedure with a maximum lag of 12 for all models. The confidence intervals for the half life estimates are based on 1500 bootstrap replications for all specifications. "a" is a test for fixed effects, "b" is the Hausman test, "c" is the Swami test for coefficient homogeneity, while "d" is a Hausman type test for coefficient homogeneity.

Table 6: Half Life Estimates (Non-Tradeable Goods)

\begin{tabular}{|c|c|c|c|c|}
\hline \multicolumn{5}{|c|}{$P_{i, t}=\sum_{j=1}^{P} \lambda_{j} P_{i, t-i}+\varepsilon_{i, t}$} \\
\hline Model & $P$ & $\overline{\sum_{j=1}^{P} \lambda_{j}}$ & Half Life & Confidence Interval \\
\hline $\mathrm{RCM}$ & 5 & 0.94537 & 14 & 6,18 \\
\hline OLS & 11 & 0.99962 & 1688 & $4, \infty$ \\
\hline Fixed Effects & 11 & 0.95367 & 18 & 3,28 \\
\hline Anderson-Hsiao & 3 & 0.9566 & 14 & $1, \infty$ \\
\hline${ }^{a} H 0: \alpha_{i}=0$ & \multicolumn{4}{|c|}{$2.56(0.000)$} \\
\hline${ }^{b} H 0: E\left(\alpha_{i}, X\right)=0$ & \multicolumn{4}{|c|}{$486.08(0.000)$} \\
\hline${ }^{c} H 0: \lambda_{i}=\lambda$ & \multicolumn{4}{|c|}{$621.44(0.000)$} \\
\hline${ }^{d} H 0: \lambda_{i}=\lambda$ & \multicolumn{4}{|c|}{$1.66(0.197)$} \\
\hline
\end{tabular}

Notes: The lag length $\mathrm{P}$ was chosen via a general to specific lag selection procedure with a maximum lag of 12 for all models. The confidence intervals for the half life estimates are based on 1500 bootstrap replications for all specifications. "a" is a test for fixed effects, "b" is the Hausman test, "c" is the Swami test for coefficient homogeneity, while "d" is a Hausman type test for coefficient homogeneity. 


\section{Figure 1}

RCM vs True

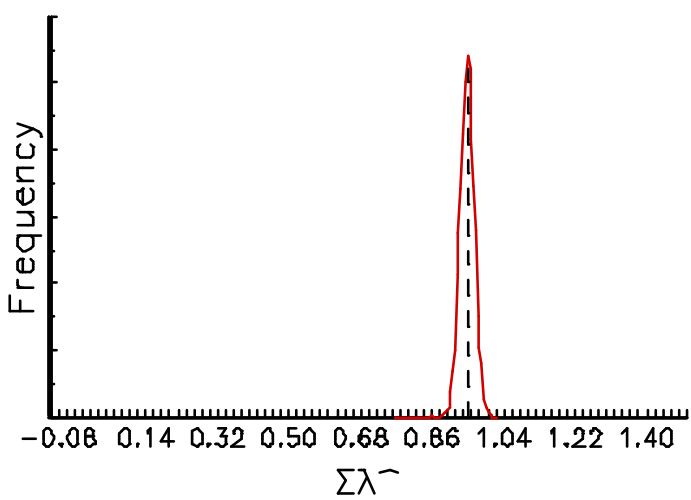

Anderson Hsioo vs True

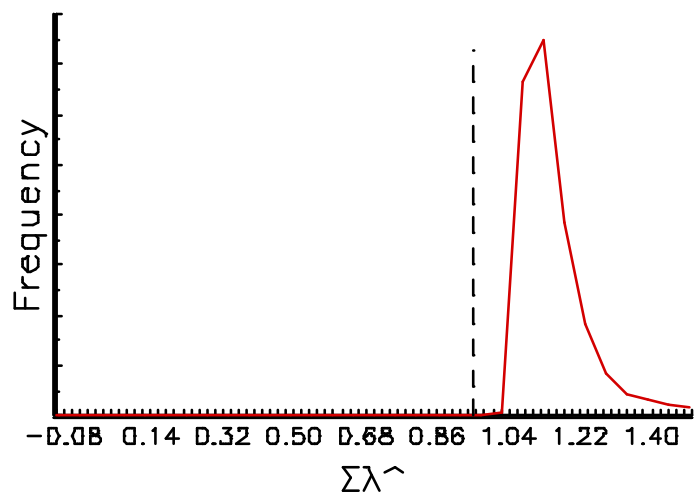

Fixed Effects vs True

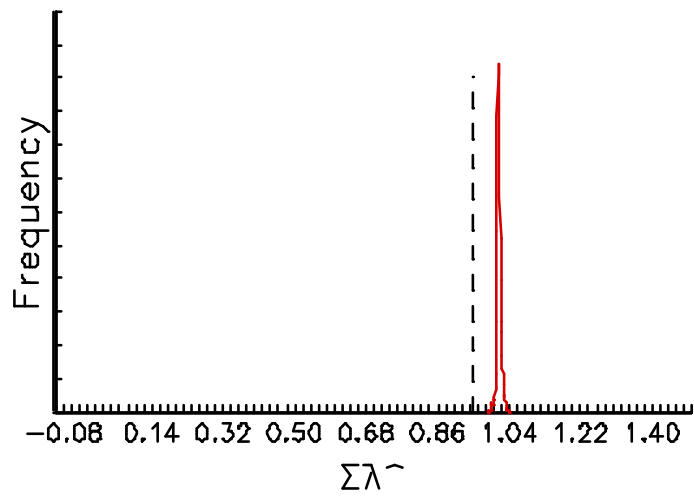

Aggregated Fixed Effects vs True

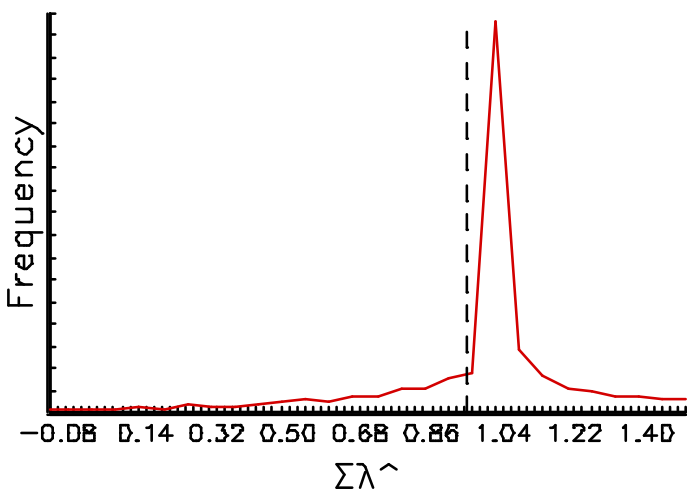

Notes:

Data was generated from the following model: $y_{i, t}=\alpha_{i}+\sum_{s=1}^{5} \lambda_{i, s} y_{i, s, t-1}+\varepsilon_{i, t}$

where $\lambda_{i, s}=\lambda_{s}+\eta_{i}, \varepsilon_{i, t} \sim N(0,1), \alpha_{i} \sim N(0,1), E\left(\eta_{i}\right)=0, E\left(\eta_{i}{ }^{2}\right)=0.0075 . \lambda_{s}$ was set equal to the estimates obtained from the RCM model. For all estimators except "Aggregate Fixed Effects", the exact dimensions of our panel were used to generate the data. Aggregate Fixed effects uses 200 cross sections with each time series equal to 100 . The generated data is then averaged over some of the cross sections to produce a dataset with $\mathrm{N}=10$ and $\mathrm{T}=100$. Fixed effects estimation is then carried out to estimate the coefficients. This is meant to simulate panel estimation with aggregated data. The figure plots the histogram of the sum of the coefficients obtained from 5000 replications and compares the distributions to the true value of $\sum_{s=1}^{5} \lambda_{s}$ represented by the dashed line. 


\section{Figure 2a}

Fixed Effects

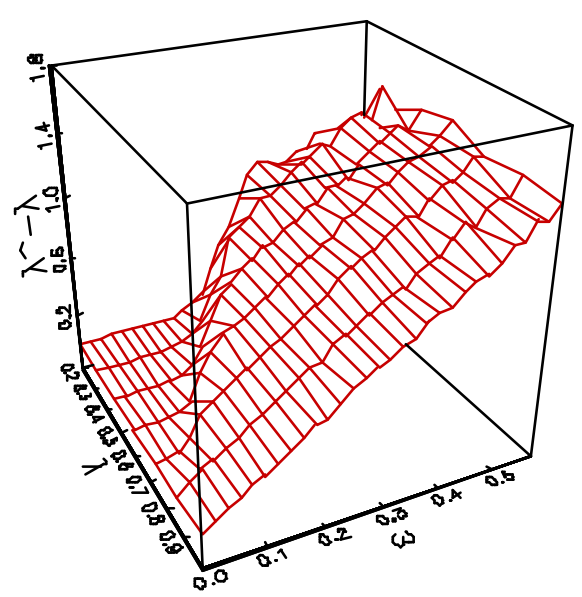

Aggregated Fixed Effects

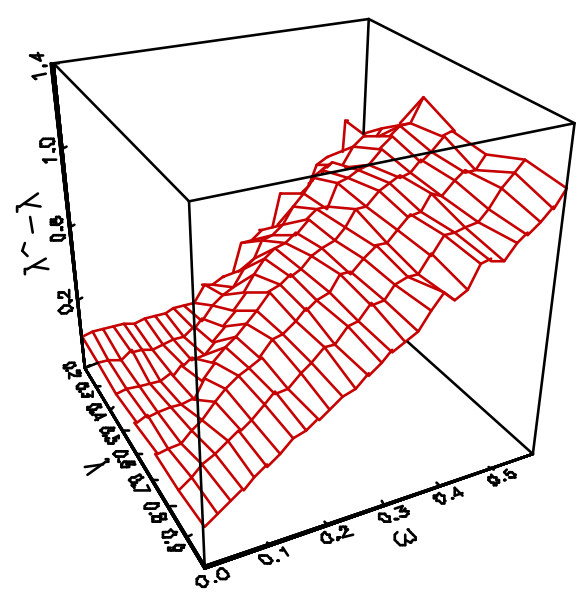

Anderson Hsigo

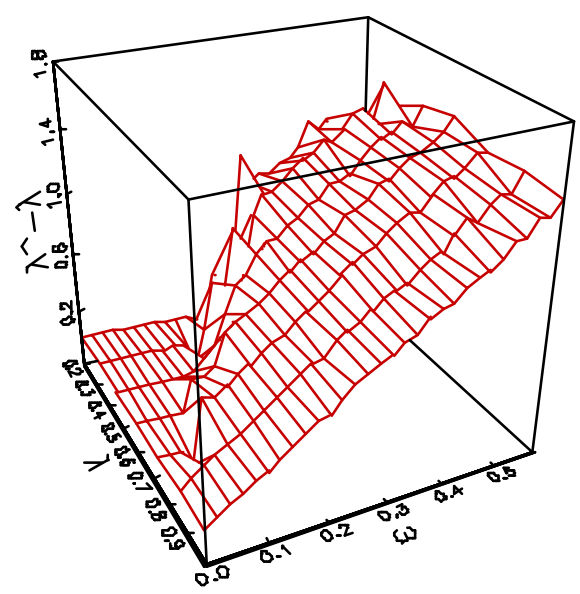

Random Coefficients

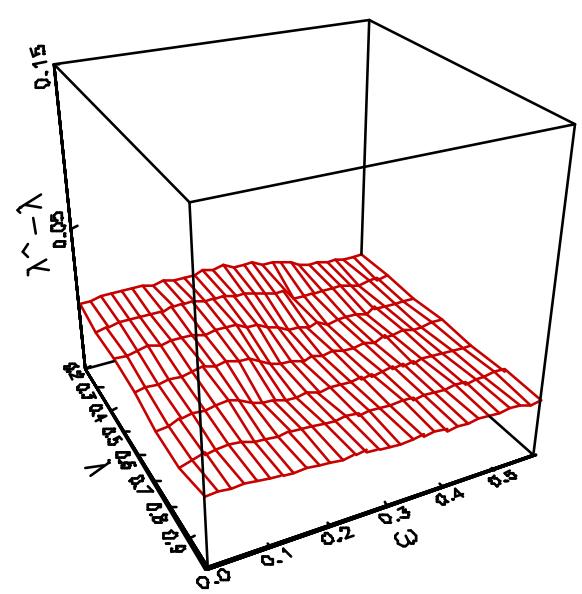

Notes:

Data was generated from the following model: $y_{i, t}=\alpha_{i}+\lambda_{i} y_{i, t-1}+\varepsilon_{i, t}$ where $\lambda_{i}=\lambda+\eta_{i}, \varepsilon_{i, t} \sim N(0,1), \alpha_{i} \sim N(0,1), E\left(\eta_{i}\right)=0, E\left(\eta_{i}{ }^{2}\right)=\bar{\omega}$. The experiment was conducted for 7 values of $\lambda=\{0.2,0.35,0.50,0.65,0.8,0.95,0.999\}$ and 30 values of $\Phi$ ranging from 0.01 to 0.59 with increments of 0.02. For all estimators except "Aggregate Fixed Effects", the exact dimensions of our panel were used to generate the data. Aggregate Fixed effects uses 200 cross sections with each time series equal to 100 . The generated data is then averaged over some of the cross sections to produce a dataset with $\mathrm{N}=10$ and $\mathrm{T}=100$. Fixed effects estimation is then carried out to estimate the coefficients. This is meant to simulate panel estimation with aggregated data. The number of replications for each combination of $\lambda$ and $\Phi$ was set equal to 100 implying that total replications equal $7 * 30 * 100=21000$. 


\section{Figure 2b}

Fixed Effects

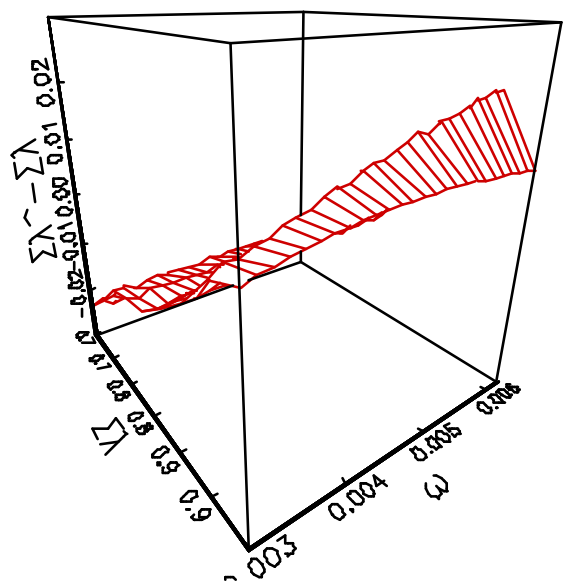

Aggregated Fixed Effects

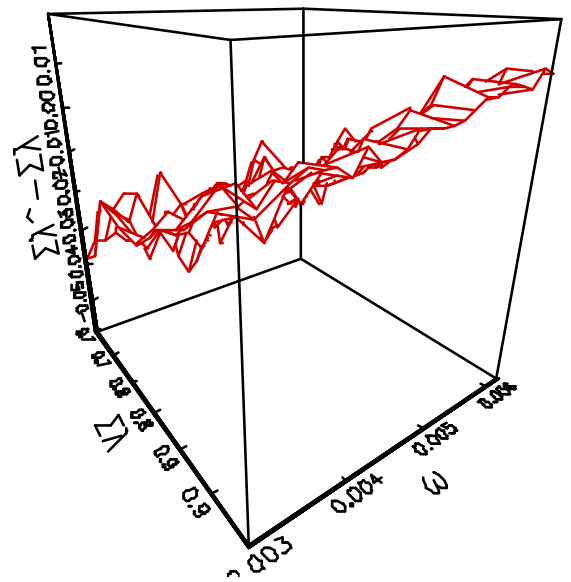

Anderson Hsigo

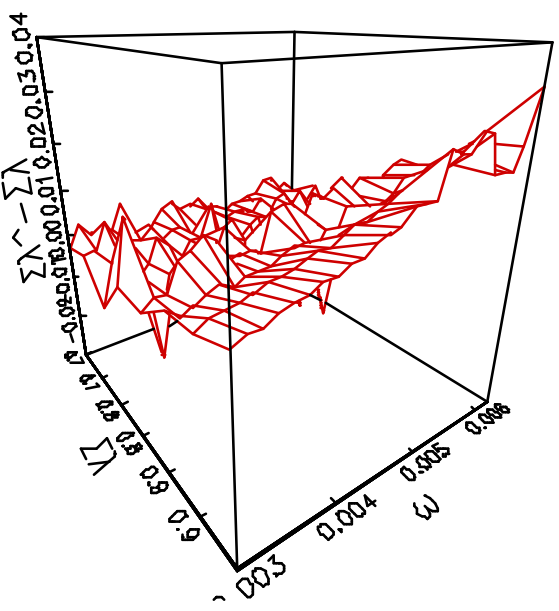

Random Coefficients

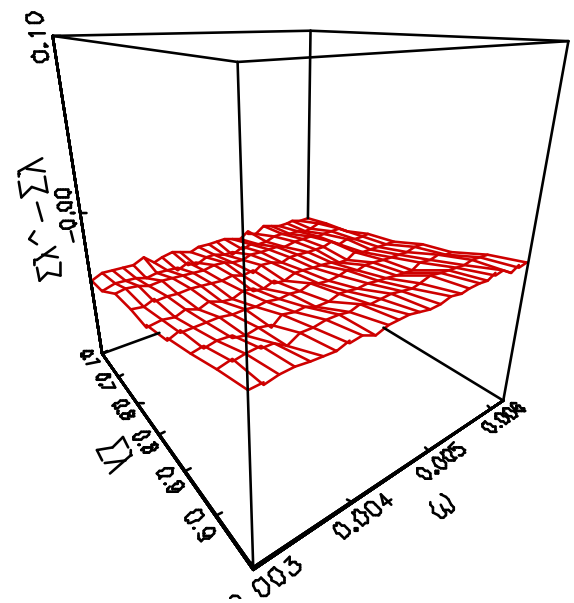

Notes:

Data was generated from the following model: $y_{i, t}=\alpha_{i}+\sum_{s=1}^{5} \lambda_{i, s} y_{i, s, t-1}+\varepsilon_{i, t}$

where $\lambda_{i, s}=\lambda_{s}+\eta_{i}, \varepsilon_{i, t} \sim N(0,1), \alpha_{i} \sim N(0,1), E\left(\eta_{i}\right)=0, E\left(\eta_{i}{ }^{2}\right)=\varpi$. The experiment was conducted for 9 values of $\lambda$ such that $\sum_{s=1}^{5} \lambda_{s} \cong\{0.69,0.79,0.89,0.91,0.92 .0 .94,0.96,0.98,0.99\}$ and 26 values of $\sqrt{\Phi}$ ranging from 0.003 to 0.005 with increments of 0.0001 . For all estimators except "Aggregate Fixed Effects", the exact dimensions of our panel were used to generate the data. Aggregate Fixed effects uses 200 cross sections with each time series equal to 100 . The generated data is then averaged over some of the cross sections to produce a dataset with $\mathrm{N}=10$ and $\mathrm{T}=100$. Fixed effects estimation is then carried out to estimate the coefficients. This is meant to simulate panel estimation with aggregated data. The number of replications for each combination of $\lambda$ and $\Phi$ was set equal to 100 implying that total replications equal $9 * 26 * 100=23400$. 